\title{
Electromagnetic atmosphere-plasma coupling: the global atmospheric electric circuit
}

Article

Accepted Version

Rycroft, M. J. and Harrison, R. G. (2012) Electromagnetic atmosphere-plasma coupling: the global atmospheric electric circuit. Space Science Reviews, 168 (1). pp. 363-384. ISSN 0038-6308 doi: https://doi.org/10.1007/s11214-011-9830-8 Available at https://centaur.reading.ac.uk/24952/

It is advisable to refer to the publisher's version if you intend to cite from the work. See Guidance on citing.

To link to this article DOI: http://dx.doi.org/10.1007/s11214-011-9830-8

Publisher: Springer

Publisher statement: The original publication is available at www.springerlink.com

All outputs in CentAUR are protected by Intellectual Property Rights law, including copyright law. Copyright and IPR is retained by the creators or other copyright holders. Terms and conditions for use of this material are defined in the End User Agreement.

$\underline{\text { www.reading.ac.uk/centaur }}$

\section{CentAUR}


Central Archive at the University of Reading

Reading's research outputs online 


\title{
Electromagnetic atmosphere-plasma coupling: The global electric circuit
}

\author{
M.J. Rycroft ${ }^{(1)}$ and R.G. Harrison ${ }^{(2)}$ \\ (1) CAESAR Consultancy, 35 Millington Road, Cambridge CB3 9HW, UK; \\ International Space University, 1 rue Jean-Dominique Cassini, 67400 Ilkirch- \\ Graffenstaden, France \\ (2) Department of Meteorology, University of Reading, Earley Gate, PO Box 243, \\ Reading, Berkshire RG6 6BB, UK \\ accepted for publication in Space Science Reviews doi:10.1007/s11214-011-9830-8
}

\begin{abstract}
A description is given of the global atmospheric electric circuit operating between the Earth's surface and the ionosphere. Attention is drawn to the huge range of horizontal and vertical spatial scales ranging from $10^{-9} \mathrm{~m}$ to $10^{12} \mathrm{~m}$, concerned with the many important processes at work. A similarly enormous range of time scales is involved from $10^{-6} \square \mathrm{s}$ to $10^{9} \mathrm{~s}$, in the physical effects and different phenomena that need to be considered. The current flowing in the global circuit is generated by disturbed weather such as thunderstorms and electrified rain/shower clouds, mostly occurring over the Earth's land surface. The profile of electrical conductivity up through the atmosphere, determined mainly by galactic cosmic ray ionisation, is a crucial parameter of the circuit. Model simulation results on the variation of the ionospheric potential, $\sim 250 \mathrm{kV}$ positive with respect to the Earth's potential, following lightning discharges and sprites are summarized. Recent experimental results comparing global circuit variations with the neutron rate recorded at Climax, Colorado, are then discussed. Within the return (load) part of the circuit in the fair weather regions remote from the generators, charge layers exist on the upper and lower edges of extensive layer clouds; new experimental evidence for these charge layers is also reviewed. Finally, some directions for future research in the subject are suggested.
\end{abstract}

Keywords: global circuit; thunderstorms; electrified cloud generators; cosmic rays; atmospheric electrical conductivity profile; fair weather regions; ionospheric potential; lightning; sprites; layer cloud electrification

\section{Introduction}

This paper is concerned with atmospheric electrical coupling from near the Earth's surface up into - and down from - the ionosphere at $\sim 80 \mathrm{~km}$ altitude and higher. This coupling takes place rapidly, at, or close to, the speed of light $c$ (Rycroft 2006), as opposed to coupling mechanisms involving mechanical waves of one type or the other which propagate at speeds much slower than $c$, and which are discussed in other papers in this volume. As outlined by Aplin et al. (2008), the subject of atmospheric electricity had its origins in the eighteenth century, grew into the concept of the global atmospheric electric circuit in the early twentieth century with the seminal papers of Wilson (1921, 1929,1956 ), and matured considerably in the first decade of the twenty first century. 
The global circuit is formed between the surface of the Earth and the ionosphere, both of which are good electrical conductors in comparison with the insulating atmosphere between them. D.C. and A.C. electric generators exist in the atmosphere, for example in thunderstorms, creating currents flowing up to the ionosphere. The current circuit closes through fair weather parts of the atmosphere that are remote from the generators. Useful background papers on different aspects of the global atmospheric electric circuit have been written by Vonnegut (1973), Makino and Ogawa (1984, 1985), Roble and Tzur (1986), Volland (1987), Hays and Roble (1979), Roble aand Hays (1979), Roble (1991), Bering et al. (1998), Rycroft et al. (2000, 2007, 2008), Williams (2002, 2009), Harrison (2004), Siingh et al. (2005, 2007, 2011), Aplin (2006), Markson (2007), Tinsley et al. (2007), Harrison et al. (2008) and Tinsley (2008). The present paper complements these papers and those which they cite. The D.C. global atmospheric electric circuit has been considered in the context of the changing climate of planet Earth by Williams (1992), Price (1993), Tinsley et al. (1994), Gray et al. (2010) and Siingh et al. (2011).

When considering a subject in physics, and its mathematical representation, the treatment conventionally begins simply, using linear theory. However, as the subject develops, it is usually appreciated that a more complex representation is appropriate. At larger amplitudes nonlinearities can arise and the system may even become chaotic on the small scale, or on the local, moderate (regional) or largest (global) scales. An important characteristic of such complex systems is that they simultaneously need to consider a wide range of spatial scales and temporal scales. Up to the present, the treatment of atmospheric electricity has remained linear, whereas nowadays climate studies often involve multi-scale and nonlinear behaviour (Donner et al. 2009; Slingo et al. 2009; Palmer and Williams 2010). The global electric circuit may be involved in climate change via non-linear electrical effects on cloud microphysical processes (Aplin et al. 2008; Carslaw 2009; Harrison and Ambaum 2008, 2010; Nicoll and Harrison 2010), as discussed later in this paper.

Fig. 1 shows the huge range of horizontal and vertical scales involved in the diverse phenomena and processes of interest which occur in the atmosphere and in the near-Earth space environment (Rycroft 2010). The horizontal scale extends over 18 orders of magnitude, and the vertical scale over 12 orders. At the Earth's surface, point discharge currents (Chalmers 1962; Ette and Utah 1973; Marcz and Bencze 1998) emanate from sharp-ended vertical conductors, such as grass and the spiky needles of coniferous trees, which have scales of millimetre size. Pointed hills and ridges have scales of kilometres to hundreds of kilometres, and the oceans longer scales, although sea spray has dimensions of millimetres.

In the lowest part of the atmosphere over continental surfaces, ionisation is generated from the escape of radon isotopes (Harrison et al. 2010) and by galactic cosmic rays arriving from beyond the solar system (Bazilevskaya et al. 2000, 2008; Velinov et al. 2009). In clean air, water vapour condenses onto these ions to form cluster ions $\sim 1 \mathrm{~nm}$ in size (Aplin et al. 2008, Rycroft et al. 2008). Some cluster ions are removed by ion-ion recombination and others are lost to aerosol particles (Harrison and Tammet 2008, 
Hirsikko et al. 2011). In some circumstances in which condensable vapours such as sulphuric acid are abundant, the cluster ions may eventually grow into $\sim 100 \mathrm{~nm}$ sized cloud condensation nuclei ( $\mathrm{CCN})$ onto which cloud droplets can form; raindrops, which are up to three orders of magnitude larger, result from coalescence of the cloud droplets. It is worth mentioning here that Enghoff et al. (2011) have recently studied sulphuric acid aerosol nucleation in an atmospheric pressure reaction vessel where a $580 \mathrm{MeV}$ electron beam has ionised the gas. They found clear evidence for an ion-induced effect on aerosol nucleation under conditions which resemble those of the Earth's atmosphere.

Also shown in Fig. 1 are low level stratiform clouds (SCs) such as stratocumulus, where the electric charges at the cloud edges are important (Nicoll and Harrison 2009, 2010), and thunderstorm cells (TCs) which can grow into large thunderstorms (Williams and Yair 2006), termed mesoscale convective systems (MCSs). Thunderstorms produce lightning discharges which radiate electromagnetic waves across a broad range of frequencies; these constitute the A.C. part of the global electric circuit, discussed later.

Above large thunderstorms transient luminous events (TLEs), such as sprites, elves and blue jets (Fullekrug et al. 2006), may occur just below the ionosphere. The lower ionosphere responds to activity from above, in the form of wave-particle interactions between whistler-mode waves from lightning and energetic electrons trapped in the magnetosphere (Rycroft 2010); extra ionization is then produced in the lowest ionosphere (Rodger et al. 2001). The magnetosphere is stimulated by activity on the Sun, that information travelling through interplanetary space in the form of coronal mass ejections (CMEs); these phenomena are generically termed space weather (Bothmer and Daglis 2007). Such phenomena (Rycroft 2010) are important in terms of possible damage to satellites and other assets in space and to humans aboard spacecraft.

Fig. 2 shows the broad range of temporal scales that are involved in the many phenomena of importance. On the shortest time scales of microseconds are electrical discharge phenomena. These are leader processes which occur as a lightning discharge progresses in steps from a thundercloud towards the ground, the cloud-to-ground (CG) return stroke which is a large ( $30 \mathrm{kA})$ current to the cloud, and intra-cloud (IC) discharges (Rakov and Uman 2003). Lightning radiates all radio frequencies from $\mathrm{MHz}$ (associated with leader processes) to $\sim 10 \mathrm{kHz}$ (where the spectrum peaks (Smith et al. 2010)) to "slow tails" ( $\sim 100 \mathrm{~Hz}$, Mullayarov et al. 2010), and to the longest wavelength electromagnetic waves occurring in the Earth's environment $(\sim 10 \mathrm{~Hz})$. These latter waves excite Schumann resonances of the spherical shell cavity between the good conducting Earth and ionosphere, the fundamental of which is at $8 \mathrm{~Hz}$ (Williams 1992; Price et al. 2007; Simoes et al. 2008; Yang et al. 2009; Shvets et al. 2010; Nickolaenko et al. 2010; Golkowski et al. 2011).

A few stations around the world can record the radiation of various frequencies generated by lightning and by sprites in order to find their location. Williams et al. (2010) did this for radio signals produced over Africa, investigating their dependence on the charge moment changes of the parent lightning. Whitley et al. (2011) have recently shown that with four stations around the world sources can be geolocated to an accuracy of $\sim 10 \mathrm{~km}$, 
which is a remarkable achievement. Shvets et al. (2009, 2010), Nakamura et al. (2010), Shvets and Hayakawa (2011) and Yamashita et al. (2011) have also presented several interesting results on these topics.

Runaway breakdown (Roussel-Dupre et al. 2008; Fishman and Chilingarian 2010) is believed to occur for some lightning discharges, possibly intra-cloud discharges (Williams et al. 2006), or active leader channels (Carlson et al. 2010). This runaway breakdown produces upward-going beams of runaway relativistic electrons which may be accelerated to a high enough energy to create a terrestrial gamma ray flash (TGF - see Fig. 2; Miller 2011). This is believed to be created as upward-going Bremsstrahlung radiation when the electrons collide with the nuclei of atmospheric atoms.

Fig. 2 also shows that, on the time scale from seconds to hundreds of seconds, blowing space charge associated with turbulence in the boundary layer from the Earth's surface up to $\sim 2 \mathrm{~km}$ altitude generates electrical fluctuations. The space charge can be primarily ionic, in clean air, or particulate, in polluted air. Particulate space charge is subject to turbulent motions, which results in electrical fluctuations. All the processes shown in figure 2 ultimately contribute to the generation of A.C. variations in the global circuit.

The electromagnetic pulse from a very large CG discharge, which transfers positive charge to ground (termed a $+\mathrm{CG}$ discharge), deposits energy in the mesosphere and creates a rapidly expanding ring of light at $\sim 90 \mathrm{~km}$ altitude, termed an elve. The consequent large electrostatic field above the thundercloud exceeds the conventional threshold field for electrical breakdown, creating a sprite from about $80 \mathrm{~km}$ at the base of the ionosphere down to about $55 \mathrm{~km}$ (Fullekrug et al. 2006; Rycroft and Odzimek 2009, 2010; Pasko 2010; Pasko et al. 2011). Rarely, blue jets appear from the top of the thundercloud. Extremely rarely, gigantic jets reach from the top of the thundercloud right up to the ionosphere - they will short circuit the gap between the Earth and the ionosphere over some area as yet to be determined.

Also shown in Fig. 2 are D.C. variations; on time scales of a fraction of an hour, these are linked to the development and evolution of thunderstorm cells. Mechanical waves occur in the form of upward propagating gravity waves, tidal variations (e.g., semi-diurnal, diurnal and two day waves), and longer period planetary waves. At even longer time scales are variations associated with the changing energy input to the stratosphere and thermosphere over the 27 day solar rotation period, annual variations, variations over the 11 year solar cycle and long term trends. The boundary between D.C. and A.C. phenomena is here shown at $200 \mathrm{~s}$, as this is the electrical time constant of the global atmospheric electric circuit, namely its resistance $\mathrm{R}$ multiplied by its capacitance $\mathrm{C}$. The capacitance is that of the spherical capacitor formed between the Earth and the ionosphere, with the dielectric atmosphere being mostly concentrated near the Earth's surface, due to gravity (Rycroft et al. 2000). 


\section{Properties of the global electric circuit}

\section{(a) Generator and load regions}

Fig. 3 is a schematic representation of the circuit taken from Rycroft et al. (2000). In the upper part the bold arrows show the flow of electric current generated by thunderstorms (on the left), and occurring over $<\sim 1 \%$ of the Earth's surface, up to the ionosphere. A tiny part of the electric current flows up into the magnetosphere along geomagnetic field line, up to the apex of each particular field line. In the fair weather part of the circuit remote from thunderstorms, the current flows down to the Earth's surface (with negative ions moving upwards). The circuit is completed by the good conductivity of land and sea surfaces and up to the base of thunderstorms by point discharge (corona) currents from sharp-tipped objects in the boundary layer. It is evident that electric charge is distributed throughout the insulating atmosphere, but most of the electric charge resides near the surface where, as is apparent from the density profile, most of the atmosphere is.

The lower part of Fig. 3 shows the equivalent circuit. It is generally believed that about a thousand thunderstorms are active globally at any one time; these are represented by a current generator (of $\sim 1$ to $2 \mathrm{kA}$ ) which acts as a D.C. battery in the circuit. The electrical resistance of the atmosphere is appreciable, especially below the thunderstorms, whereas the ionospheric resistances shown are by comparison extremely small, effectively ensuring that the ionosphere is an equipotential; its potential, $\mathrm{V}_{\mathrm{I}}$, is $\sim 250 \mathrm{kV}$ positive with respect to the Earth's surface.

As well as thunderstorms, there is another significant generator in the global circuit. This is due to electrified rain/shower clouds which generally bring negative charge to the ground on raindrops (Liu et al. 2010), as was first discussed by Wilson (1921). Rycroft at al. (2007) estimated that thunderstorms contribute about $60 \%$ of the upward current to the ionosphere, with electrified rain/shower clouds being responsible for $\sim 40 \%$. Odzimek et al. (2010) deduced that these percentages are $80 \%$ and $20 \%$, respectively. A very recent paper by Mach et al. (2011) has, for the first time, used experimental data from aircraft and satellites to deduce that thunderstorms over the land contribute $1.1 \mathrm{kA}$ to the global circuit and, over the oceans, $0.7 \mathrm{kA}$. The contributions to the global circuit made by rain/shower clouds are $0.22 \mathrm{kA}$ for ocean storms and $0.04 \mathrm{kA}$ for storms over the land. Thus, Mach et al. (2011) consider that thunderstorms contribute $90 \%$ and rain/shower clouds $10 \%$ to the total $\sim 2 \mathrm{kA}$ flowing in the global circuit.

In the return (or load) part of the circuit in the fair weather region (over $\sim 98 \%$ of the Earth's surface in area) the downward current density $\mathrm{J}_{\mathrm{z}}$ flowing is $\sim 2 \mathrm{pAm}^{-2}$ (Wilson 1921). Most of the resistance is near the surface, due to the exponential distribution of the atmospheric density with a scale height $\mathrm{H}$ of $\sim 7 \mathrm{~km}$. The equivalent load resistor of the entire circuit, $\mathrm{R}$, is $\sim 200 \mathrm{Ohms}$. The lower right corner shows that the capacitance $\mathrm{C}$ of the circuit is the value calculated by the standard electrostatics method. Here, $R_{E}$ is the Earth's radius, and the separation between the two conductors is taken as the scale height $\mathrm{H}$ of the dielectric atmosphere rather than their physical separation, which is almost 12 times greater. The negative charge on the Earth's surface is $-2 \times 10^{5}$ Coulombs, and the electric energy stored in the circuit is $\sim 2 \times 10^{10} \mathrm{~J}$. 
The conductivity and the electric current density $\mathrm{J}_{\mathrm{z}}$ flowing in the fair weather regions determine the vertical electric field E. Near the Earth's surface away from aerosol pollution in fair weather $\mathrm{E}=-130 \mathrm{~V} / \mathrm{m}$; the minus sign indicates that the electric field is directed downwards. Meteorologists refer to this as the potential gradient (PG) rather the electric field; the PG and E have the same magnitude, but by convention the PG is positive in fair weather.

\section{(b) Vertical variations}

The cosmic ray fluxes at different altitudes and for different rigidities (i.e. for different momenta) have been reported by Bazilevskaya et al. $(2000,2008)$ and Stozhkov et al. (2001). In the presence of the geomagnetic field, protons with rigidities $<0.6 \mathrm{GV}$ can only gain access to the Earth's environment in the polar regions; those with rigidities between 2.5 and $6 \mathrm{GV}$ are found at middle latitudes, and only those with rigidities of 13.5 GV or more can enter the magnetosphere at equatorial latitudes. Fig. 4, from Bazilevskaya et al. (2000), shows, in panel (a), long term observations of the fluxes (J) of cosmic rays of different rigidities $\left(\mathrm{R}_{\mathrm{c}}\right)$ at 33 degrees magnetic latitude $(6.7 \mathrm{GV}), 51$ degrees magnetic latitude $(2.4 \mathrm{GV})$ and 64 degrees $(0.6 \mathrm{GV})$ at 25 to $30 \mathrm{~km}$ altitude in the middle atmosphere; panel (b) shows similar data in the upper troposphere between 6 and $12 \mathrm{~km}$ altitude.

There is a strong solar cycle variation, with large fluxes near the solar minima around 1965, 1976, 1987 and approaching 1998. In the troposphere the cosmic ray flux at high latitudes is typically $\sim 20 \%$ larger in solar minimum conditions that near solar maximum; it is $\sim 10 \%$ larger at 33 degrees magnetic latitude. The ion-pair production rate at different altitudes varies by $\sim 2.5$ as one moves from the geomagnetic equator to the magnetic poles. The principal nuclear species contributing to the cosmic ray spectrum have been presented recently by Nakamura et al (2010) and Schwarzschild (2011).

Because the conductivity of the atmosphere is least near the Earth's surface, most of the electrical resistance of the circuit lies there. Harrison and Bennett (2007) and Rycroft et al. (2008) have published diagrams showing that $\sim 95 \%$ of the atmospheric columnar resistance $R_{c}$ lies at altitudes below $10 \mathrm{~km}$, with half of the columnar resistance being within the lowest $1.6 \mathrm{~km}$. Fig. 5 displays a graph of the percentage of the columnar resistance calculated at height increments of $1 \mathrm{~km}$ from the surface up to $10 \mathrm{~km}$ height; its value is $156 \mathrm{POhms} . \mathrm{m}^{2}$. The value of $\mathrm{R}_{\mathrm{c}}$ all the way up to the ionosphere is $167 \mathrm{POhms} . \mathrm{m}^{2}$. In the fair weather part of the circuit, it is obvious from Ohm's Law that $\mathrm{J}_{\mathrm{Z}}=\mathrm{V}_{\mathrm{I}} / \mathrm{R}_{\mathrm{c}}$. Inserting the model values which we have presented, $\mathrm{J}_{\mathrm{z}}$ is found to be $250 \mathrm{kV} / 167 \mathrm{POhms} . \mathrm{m}^{2}=1.5 \mathrm{pAm}^{-2}$, which is consistent with many experimental determinations, such as the original direct measurements of Wilson (1906).

Thus, it is evident that the atmospheric (or planetary) boundary layer is the most important load in the fair weather part of the global circuit. When considering how the global circuit operates, it is most important to realise this fact. Also, as mentioned earlier, most of the positive charge distributed through the atmosphere resides near the surface; it 
is not on the ionospheric upper conductor of the capacitor. Nogueira (2009) has constructed a finite element model of the fair weather electric circuit.

In order to perform model calculations, Rycroft et al. (2007) and Rycroft and Odzimek (2010) plotted a realistic average model of the electrical conductivity profile through the Earth's atmosphere. The conductivity increases by seven orders of magnitude from the surface, where the conductivity is $\sim 10^{-14} \mathrm{~S} / \mathrm{m}$, to $\sim 10^{-7} \mathrm{~S} / \mathrm{m}$ at $\sim 80 \mathrm{~km}$ altitude; Odzimek et al. (2010) have presented more complicated models displaying geographic variations. Using the simpler conductivity model, Rycroft et al. (2007) and Rycroft and Odzimek $(2009,2010)$ constructed an electrical engineering model of the global atmospheric electric circuit, which they used to evaluate the effects of lightning having different charge moment changes and of sprites on the potential of the ionosphere and also to show how sprites develop.

Rycroft et al. (2007, 2008) and Rycroft and Odzimek (2010) briefly discussed some relevant experimental observations of atmospheric electric fields, currents and air conductivities made from different balloons at altitudes up to $35 \mathrm{~km}$. Thomas et al. (2009) reviewed the literature on these topics. Further, they presented the results of making such observations in the stratosphere (between 30 and $35 \mathrm{~km}$ ) above an active thunderstorm in southeastern Brasil. They found that the conductivity was about $8.5 \times 10^{-}$ ${ }^{12} \mathrm{~S} / \mathrm{m}$; for their model thunderstorm of radius $\sim 60 \mathrm{~km}$, they estimated that the upward current above this active thunderstorm was $\sim 2$.5.A. In relation to the results presented in the previous section (a), they reported that "the overall charge removal contribution of large $+\mathrm{CG}$ flashes to the global circuit was small".And, "moreover, since the -CG flashes provide charging and $+\mathrm{CG}$ flashes provide discharging of nearly equal magnitudes, we conjecture that the combined contribution due to all lightning could be very small. These results are in good agrement with those presented by Rycroft et al. (2007) and Rycroft and Odzimek (2010).

Inside an active thundercloud, the electrical conductivity is not well-constrained, but observations discussed by Rycroft et al. (2007) show that it is at least a factor of six less than its value in the clear air surrounding the thundercloud; Rycroft et al. $(2007,2008)$ showed values for a model thundercloud. Fig. 3 of the Rycroft and Odzimek (2010) model considered the effect on the global circuit of reducing the conductivity within the thundercloud by a factor ranging from 2 to 29 . They reported that the ionospheric potential would then increase from $\sim 150 \mathrm{kV}$ to $\sim 415 \mathrm{kV}$.

Similarly, but inside a stratiform cloud in the fair weather region of the global circuit, the conductivity is less that just outside the cloud. By Gauss' law of electrostatics, there has to be an electric charge at the top and bottom edges of a uniform stratiform cloud, and the current flows through the cloud with the same current density value as above and below it. This topic is the subject of recent experimental studies by Nicoll and Harrison (2010) which are discussed in section 3(d).

With the increase in conductivity with height, the vertical electric field becomes so small with increasing height that the potential in the model atmosphere at $60 \mathrm{~km}$ is only $24 \mathrm{~V}$ 
less than the 250,000 kV ionospheric potential (Rycroft et al. 2007). Since these potentials are the same to within one part in $10^{4}$, we may say that the $60 \mathrm{~km}$ level is the height of the electrosphere. Chalmers (1967) defined the electrosphere as being at the level at which, horizontally, essentially the same electric potential exists.

However, this concept does not allow for the presence of electric fields arising from magnetospheric sources (Tinsley 2008), such as the flow of the solar wind past the magnetosphere (Rycroft 2010). This value of this additional electric field depends strongly on the value ( $\sim$ some nT) of the southward component of the interplanetary magnetic field (often called the IMF). It also depends, to a lesser extent, on the sign and magnitude of the dawn-to-dusk component of the interplanetary magnetic field. Tinsley (2008) splits the atmospheric columnar resistance into two parts - a tropospheric part and a stratospheric part - the latter is much smaller than the former. The magnitude of the stratospheric part varies markedly with latitude, because of the latitudinal variation of the ionisation source. Tinsley et al. (2007) and Zhou and Tinsley (2010) emphasise the generator provided by coupling from the solar wind.

Electric currents flowing in the atmosphere find it easier to continue upwards into a region of ever-increasing conductivity than to flow horizontally. This statement is true, above the electrosphere, up to and through the lower ionosphere. It is even true through the ionospheric dynamo field region at $\sim 100$ to $\sim 130 \mathrm{~km}$ altitude (Rishbeth and Garriott 1969; Kelley 2009). Thus, small currents flow up to the apex of the geomagnetic field line at that particular L-value (McIlwain 1961). (The McIlwain parameter L is, essentially, the distance measured (in Earth radii) from the centre of the Earth to where that magnetic field line crosses the equatorial plane. The geomagnetic latitude of the foot of the field line on the Earth's surface, $\lambda$, is related to $L$ by the equation $L \cdot \cos ^{2} \lambda=1$.) Stansbery et al. (1993) estimate that half of the current that reaches the ionosphere flows into the geomagnetically conjugate hemisphere.

Fig. 6 plots some results of the Rycroft et al. (2007) model on properties of the fair weather field. Panel a) on the left shows the height variation of the electric potential, from which the vertical electric field is calculated; that is shown in panel b). The consequent electric charge density is found from Gauss' law, and plotted in panel c) on the right hand side of the figure. In the free atmosphere, at a few $\mathrm{km}$ altitude, the charge density is only $\sim 0.1 \mathrm{pC} / \mathrm{m}^{3}$.

\section{Recent findings concerning the global circuit}

\section{(a) Source term}

Fig. 7 shows the position of the RHESSI satellite when it detected a TGF (taken from Smith 2009; more results are given by Smith et al. 2010). The TGFs occur over land and sea, preferentially over tropical thunderstorms where the troposphere can be as high as 18 $\mathrm{km}$. This indicates that the TGFs may well originate in or above IC discharges up to the positive charge at the top of an energetic tropical thundercloud (Stanley et al. 2006; Willams et al. 2006; Lu et al. 2010). The lack of events observed over Brazil and to the East is due to the instrument being switched off as the satellite travels through the inner 
van Allen radiation belt (Rycroft 2010) in the vicinity of the South Atlantic Geomagnetic Anomaly (SAGA); here, the intense radiation may otherwise cause the satellite's electronic systems to fail.

Whilst it is not proven that TGFs play a role in maintaining the global circuit, it is important to consider the impact of relativistic processes taking place above thunderstorms on the global circuit. Carlson et al. $(2009,2010)$ suggest that TGF production is associated with current pulses $(\sim 1 \mathrm{~ms})$ in lightning leader channels and runaway processes, and they have produced promising simulations. The three brightest TGFs observed aboard the Fermi satellite (Briggs et al. 2011) have relativistic electronpositron beams associated with them. Fishman (2011) has discussed the behaviour of these electrons and positrons moving along geomagnetic field lines at low L-shells. Fullekrug et al. (2011) have simulated the production of relativistic electrons above a thundercloud and below a sprite, which casn radiate radio waves with frequencies up to $400 \mathrm{kHz}$. They note that such "relativistic electron beams are a new form of impulsive energy transfer between thunderclouds and the middle atmosphere which need to be considered as a novel element in the global atmospheric electric circuit”.

The long term global distribution of lightning discharges, derived at latitudes up to 38 degrees North and South from data from the Lightning Imaging Sensor (LIS) on a satellite, is shown in Fig. 8. Three centres of activity lie over South East Asia (sometimes called the maritime continent), central Africa and South America. At these three different meridians, their activity peaks daily at around 1500 local time, as a result of daytime solar heating of the Earth's surface which stimulates enhanced atmospheric convection. It is clear that over the land the number of lightning discharges is typically a hundred times greater than over the tropical oceans. Earlier satellite data (Christian et al. 2003) gave the number of flashes per square $\mathrm{km}$ per year. Globally, there are about 44 flashes per second, of which less than one is over the oceans. For these discharges, in one second, 33 are likely to be intra-cloud (IC) discharges, $10-\mathrm{CG}$ discharges and $0.7 \mathrm{a}+\mathrm{CG}$ discharge (Christian et al. 2003).

Price (2006) plotted (his Fig. 8) the Universal Time variation of the thunderstorm area of the three tropical continental regions. The sum of these three UT curves gives the global thunderstorm activity as a function of UT. It has a minimum at 03 UT and a broad maximum from 14 to 19 UT. Measurements made during the 1920s aboard the research ship Carnegie showed that the mean PG under fair weather conditions of clear sky varied in a very similar way to the global thunderstorm activity, thereby demonstrating that thunderstorms are an important driver of the global atmospheric electric circuit. The UT variation of thunderstorm activity is called the Carnegie Curve, and shown as Fig. 8(b) of Price (2006).

(b) Current flow and ionospheric potential

Integrating the vertical electric field profile measured aboard aircraft or balloons up to the troposphere essentially determines the ionospheric potential. At 12 UT this has the value $250 \mathrm{kV}$, and it rises to $310 \mathrm{kV}$ at 16 and $20 \mathrm{UT}$; it then falls to $200 \mathrm{kV}$ at $24 \mathrm{UT}$. The curve closely resembles the Carnegie Curve (Markson 1986), which is one of the 
"confirming ideas" (Aplin et al, 2008) supporting the behaviour of the Earth-atmosphere global circuit system. A significant generator of the conduction currents up to the ionosphere (also known as Wilson currents) is due to the action of thunderstorms which act as batteries.

Harrison and Bennett (2007) considered the observations made on some days, in different years from 1966 to 1971, using electric field sensors carried on balloons launched from Weissenau, Germany, from which the ionospheric potential was derived by vertical integration. The results were compared with fair weather observations made on the same days at the Kew observatory, on the outskirts of London. A good fit to a linear model, plotting the ionospheric potential normalised by the PG at Kew against the derived surface air conductivity at Kew, was found. This indicates that global circuit concept holds over an area at least as great as the size of Europe.

\section{(c) Global circuit modulation}

Next, we investigate studies of the response of the global atmospheric electric circuit to changes of the flux of cosmic rays in order to test our understanding of the global circuit. Measurements of the conduction current show a positive response to cosmic ray changes, driven by the solar cycle (Markson, 1980; Harrison and Usoskin, 2010). Panel (a), from Harrison and Usoskin (2010), demonstrates the response observed in $V_{\mathrm{I}}$. It shows as individual symbols the ionospheric potential observed from several different investigators on specific days; this usually lies between 150 and $300 \mathrm{kV}$.

At the bottom of the panel is plotted the daily neutron count rate as observed at Climax, Colorado, USA. This indicates the flux of galactic cosmic rays with rigidities $>3 \mathrm{GV}$. At solar maximum, around the year 1970, the cosmic ray flux is $\sim 12 \%$ less than nearer solar minimum (1966 and 1972-1973). This is because the scattering of cosmic rays by irregularities in the solar wind and the interplanetary magnetic field which it carries out into the heliosphere is enhanced at solar maximum. If the conductivity varies as the square root of the ion production rate (Rycroft et al. 2008), as expected in marine air where there is no radon contribution, nor appreciable ion removal by aerosol, it will be $6 \%$ less near solar maximum.

The straight line fit presented in panel (b) of Fig. 9 (Harrison and Usoskin 2010) shows that the ionospheric potential is $\sim 17 \%$ less at solar maximum (when the Climax neutron

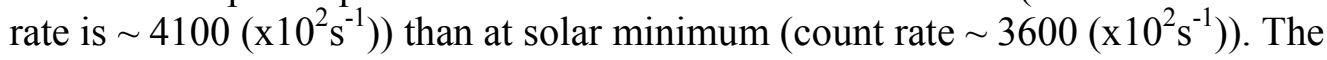
atmospheric conductivity is less at solar maximum than at solar minimum and the ionospheric potential is accordingly less. Also the fair weather current density is $\sim 23 \%$ less at solar minimum than at solar maximum (Harrison and Usoskin 2010); that result is in good agreement with the $6 \%$ conductivity change and the $17 \%$ potential change. The conclusion that can be drawn without doubt from these figures is that the flux of cosmic rays affects the global circuit.

(d) Global circuit cloud coupling

This modulation of the fair weather current density by solar activity and associated cosmic ray changes provides a potential mechanism whereby the properties of clouds at 
low heights in fair weather regions could be changed by the currents passing through them, with implications, currently not quantified, for changes in weather and climate as a result. Theory indicates that, at the edge of a horizontal layer cloud, the transition from low conductivity air within a cloud to air of greater conductivity outside the cloud will be accompanied by a region of enhanced space charge, when the current flows vertically through the cloud boundary. Nicoll and Harrison (2009) have confirmed empirically that current flow passes through layer clouds.

Nicoll (2010) and Nicoll and Harrison (2010) have described an ingenious cloud edge charge detector (CECD) carried aloft by a meteorological balloon to investigate layer cloud edges at high vertical resolution. At the bottom of a low level cloud, an instrumented aircraft detected cloud droplets, as indicated in panel (a) of Fig. 10. From the balloon data, in a region where $J_{z}$ is $\sim 2 \mathrm{pAm}^{-2}$, the air conductivity was calculated using the observed droplet properties. This is shown in panel (c) of Fig. 10 as the dark curve, with the lower scale. In this stratiform cloud in the fair weather part of the circuit, the conductivity is found to be three times less than that outside it. At the cloud edge, the negative space charge as a result of Gauss' law is up to $35 \mathrm{pCm}^{-3}$. The equivalent mean charge per droplet would be that of a few elementary electronic charges, but this would vary with droplet size size. It is believed that these charges are sufficient to influence collision processes between small cloud droplets in stratiform clouds.

The difficulty in determining the sensitivity of clouds to such changes, empirically at least, is the need to remove the substantial natural variability commonly present in cloud and clearly evident from satellite images of planet Earth. In one approach, Kniveton et al. (2008) investigated changes of the cloud cover at Vostok, Antarctica, and extreme increases of the vertical electric field there. Harrison and Ambaum (2010) reported a median $10 \%$ reduction in cloud amount at Lerwick Observatory, on the Shetland Islands to the north-east of Scotland, at $\mathrm{L} \sim 4$, during Climax neutron rate reductions of at least $10 \%$ (Fig. 11). However, at a single site there is always substantial variability in the cloud data, which, even with averaging over multiple events, usually dominates. This result is not inconsistent with a cosmic ray effect on the global circuit which also influences clouds through a conduction current mechanism, and the analysis indicates rapid time scales of $\sim 1$ day or less.

Other than cosmic ray step changes, an alternative method of identifying cloud and global circuit responses to cosmic rays is to use spectral analysis methods to identify periodicities which are unique to cosmic rays. For example, a 1.68 year quasi-periodicity is known to occur from time to time in cosmic ray data (Valdes-Galicia et al. 1996), which is generated in the heliosphere rather than the photosphere (Rouillard and Lockwood, 2004). A similar periodicity is apparent in surface PG data at Nagycenk Observatory, Hungary (Harrison and Marcz 2007), during fair weather conditions but absent during disturbed weather when global circuit influences would be masked.

Applying this spectral approach to a long series of cloud data from Lerwick, Harrison (2008) showed that a 1.68 year quasi-periodicity was also present during 1978-1990 when the periodicity was strong in neutron counter data. Specifically, this periodicity was 
found on days which were overcast. Hence, if the signal detected in the clouds originated in cosmic rays, this would not be inconsistent with a cloud edge response to modulation of the conduction current.

As common periodicities can arise by chance, a further requirement is for phase matching of the similar periodicities observed. Fig. 12 shows a combination of neutrons (a) and Lerwick cloud data (c), filtered as in Harrison (2008), but with the short period of conduction current data available from Lerwick around the same time (Harrison and Nicoll, 2007), panel (b). As must be expected with an intermittent and short data series, the periodicity after filtering the conduction current is well within the range expected to be produced by noise. However, a similar phase response is apparent in each of the neutron counter, conduction current and cloud data series, which, at the periodicity considered, is not inconsistent with a heliospheric signal propagating through the global circuit into cloud. Further work (Harrison et al. 2011), has shown that the cloud base at Lerwick also varies with cosmic rays, as might be expected from changes in the lower edge of clouds. This response was apparent in clouds identified by a trained meteorological observer as layer clouds.

\section{(e) Applications of global atmospheric electricity}

The potential gradient (PG) in surface air is sensitive to aerosol pollution, because of the removal of ions by aerosol particles. In severely polluted air, the PG can be substantially raised and, since historically many measurements were made in urban regions, this provides a method by which past urban pollution information can be reconstructed (Harrison and Aplin 2002, 2003; Harrison, 2006, 2009).

At a regional scale Harrison et al. (2010) have discussed how radon emanating from the land (but not the oceans) in larger amounts than usual before a major earthquake increases the atmospheric conductivity in the surface layer, the lowest $250 \mathrm{~m}$ of the atmosphere. This reduces the columnar resistance to the ionosphere and, in a fair weather region, the current to the ionosphere increases. The PG before a major earthquake should therefore be reduced, as has previously been observed (Kondo, 1968). The associated increased current, i.e. the increased upwards flow of negative ions, has the effect of lowering the ionosphere and so increasing the cut-off frequency $(\sim 1.7 \mathrm{kHz})$ for radio waves propagating in the Earth-ionosphere waveguide.

This mechanism accounts for the observations of the changed radio noise observed by the Demeter satellite over regions before major earthquakes occur (Nemec et al. 2009). It would be interesting to observe the cut-off frequency of "tweeks" (Reeve and Rycroft 1972), signals from distant lightning propagating at night over the earthquake-affected region in order to test the prediction of this mechanism where precursors to major earthquakes occurring over land affect the ionosphere. Pulinets and Ouzounov (2010) have presented a more complex mechanism relating these observable phenomena, and others. Mechanical (i.e. acoustic or gravity wave, or tidal, mechanisms to account for such effects have been considered by Hayakawa (2011). Hayakawa et al. $(2005,2008)$ have reported some anomalous third and fourth harmonic Schumann resonance effects associated with earthquakes. 


\section{Concluding remarks}

In this paper we have outlined the physical processes operating in the D.C. and A.C. global atmospheric electric circuit which rapidly couple phenomena occurring near the Earth's surface with the ionosphere and the near-Earth space environment.

Finally, we suggest some studies which could advance the subjects discussed further. It seems to be desirable to:

(i) investigate in more detail the relative contributions made by thunderstorm generators and by rain/shower cloud generators as drivers of the global electric circuit (Liu et al. 2010; Mach et al. 2011),

(ii) study the effects of cosmic rays (especially Forbush decreases) on lightning (Chronis 2009), low level clouds (Harrison et al. 2011), and their effects in the fair weather (load) part of the global circuit,

(iii) investigate land/ocean differences in greater detail (Kulkarni 2009),

(iv) study the energy densities of the many different physical processes involved (see Feldstein et al. 2003),

(v) continue the search for signatures in the vertical electric field observed near the Earth's surface and throughout the atmosphere due to

(a) solar flares (see Cobb 1967; Holzworth 1981; Kasatkina et al. 2010) or coronal mass ejections (see Kumar et al. 2008),

(b) Forbush decreases (see Roble 1985; Sapkota and Varshnaya 1990; Marcz (1997),

(c) solar proton events (see Willett 1979; Farrell and Desch 2002),

(d) auroral activity (see Hale and Croskey 1979; Belova et al. 2001;

Kleimenova et al. 2010), and

(e) gigantic jets (see Riousset et al. 2010),

(vi) conduct a variety of novel observations in space (ASIM, Chibis, Firefly, GLIMS, Sprite-sat, and TARANIS), and

(vii) test experimentally the hypothesis that radon emanating from the land before a major earthquake lowers the ionosphere.

\section{Acknowledgements}

We thank many colleagues around the world for discussions over a good number of years on the topics presented here. This work partly results from an ISSI team project Study of cosmic ray influence upon atmospheric processes.

\section{References}

K.L. Aplin, Surv. Geophys. 27, 63 (2006)

K.L. Aplin, R.G. Harrison, M.J. Rycroft, Space Sci. Rev.137, 11 (2008)

G.A. Bazilevskaya, M.B. Krainev, V.S. Makhmutov, J. Atmos. Sol. Terr. Phys. 62, 1577 (2000) 
G.A. Bazilevskaya, I.G. Usoskin, E.O.Fluckiger, R.G.Harrison, L Desorgher, R.

Butikofer, M.B.Krainev, Y.I.Stozhlov, A.K. Svirzhevskaya, N.S. Svirzhevsky, G.A.

Kovaltsov, Space Sci. Rev. 137, 149 (2008)

E. Belova, S. Kirkwood, H. Tammet, Ann. Geophys. 18, 1623 (2001)

E.A. Bering, A.A. Few, J.R. Benbrook, Phys. Today 51, 24, October (1998)

V. Bothmer, I.A. Daglis, Space weather - physics and effects, Springer Praxis, Berlin, Heidelberg New York (2007)

M.S. Briggs, V. Connaughton, C. Wilson-Hodge, R.D. Preece, G.J. Fishman, R.M.

Kippen, P.N. Bhat, W.S. Paciesas, V.L. Chaplin, C.A. Meegan, A. von Kienlin,J. Greiner J.R. Dwyer, D.M. Smith, Geophys. Res. Lett. 38, L02808 (2011)

doi:10.1029/2010GL046259

B.E. Carlson, N.G. Lehtinen, U.S. Inan, J. Geophys. Res. 114, A00E08 (2009) doi:10.1029/2009JA014531

B.E. Carlson, N.G. Lehtinen, U.S. Inan, J.Geophys. Res. 115, A10324 (2010) doi:10.1029/2010JA015647

B.E. Carlson, N.G. Lehtinen, U.S. Inan, J. Geophys. Res. 115, A10324 (2010) doi:10.1029/2010JA015647

K. Carslaw, Nature 460, 332 (2009)

J.A. Chalmers, J. Atmos. Terr. Phys. 24, 1059 (1962)

J.A. Chalmers, Atmospheric electricity, second edition, Pergamon, Oxford (1967)

H.J. Christian, R.J. Blakeslee, D.J. Boccippio, W.L. Boeck, D.E. Buechler, K.T. Driscoll, S.J. Goodman, J.M. Hall, W.J. Koshak, D.M. Mach, M.F. Stewart, J. Geophys. Res. 108 (D1), 4005 (2003)

T.G. Chronis, J. Clim. 22, 5748 (2009)

W.E. Cobb, Monthly Weather Rev. 95, 905 (1967)

R. Donner, S. Barbosa, J. Kurths, N. Marwan, Eur. Phys. J. Special Topics 174, 1 (2009)

M.B. Enghoff, J.O.P. Pedersen, U.J. Uggerhoj, S.M. Paling, H. Svensmarek, Geophys, Res. Lett. 38, L09805 (2011) doi:10.1029/2011GL047036

A.I.I. Ette, U. Utah, J. Atmos. Terr. Phys. 35, 785 (1973) 
W.M. Farrell, M.D. Desch, Geophys. Res. Lett. 29, 1323 (2002)

Y.I. Feldstein, I.A. Dremukhina, A.E. Levitin, U. Mall, I.I. Alexeev, V.V. Kalegaev, J. Atmos. Sol. Terr. Phys. 65, 429 (2003)

G. Fishman, A. Chilingarian, EOS, Trans. Amer. Geophys. Un. 91, 446 (2010)

G.J. Fishman, EOS, Trans. Amer. Geophys. Un. 92, 185 (2011)

doi:10.1029/2011EO220001

M. Fullekrug, E.A. Mareev, M.J. Rycroft (eds), Sprites, elves and intense lightning discharges, Springer, Dordrecht, The Netherlands (2006)

M. Fullekrug, R. Roussel-Dupre, E.M.D.Symbalisty, J.J. Colman, O. Chanrion, S. Soula, O. van der Velde, A. Odzimek, A.J. Bennett, V.P. Pasko, T. Neubert, Atmos. Chem. Phys. 11, 7747 (2011)

M. Golkowski, M. Kubicki, M. Cohen, A. Kulak, U.S. Inan, Acta Geophysica 59, 183 (2011)

L.Gray, J. Beer, M. Geller, J.D. Haigh, M. Lockwood, K. Matthes, U. Kubasch, D.

Fleitmann, G. Harrison, L. Hood, J. Luterbacher, G.A. Meehl, D. Shindell, B. van Geel, W. White, Rev. Geophys. 48 (2010) doi:10.1029/2009RG000282

L.C. Hale and C.L. Croskey, Nature 278, 239 (1979)

R.G. Harrison, Surv. Geophys. 25, 441 (2004)

R.G. Harrison, Atmos Environ 40, 18, 3327 (2006) doi: 10.1016/j.atmosenv.2006.01.042

R.G. Harrison, K.L Aplin, Atmos Environ 36, 254037 (2002)

R.G. Harrison, K.L Aplin, Atmos Environ 37, 5319 (2003)

doi:10.1016/j.atmosenv.2003.09.042

R.G. Harrison, A.J. Bennett, Adv. Geosciences, 13, 17 (2007)

R.G. Harrison, F. Marcz, Geophys. Res. Lett. 34, L23816 (2007)

doi:10.1029/2007GL031714

R.G. Harrison, Proc. Roy. Soc. A, 454, 2575 (2008)

R.G. Harrison, Atmos Environ 43, 1364-1366 (2009)

http://dx.doi.org/10.1016/j.atmosenv.2008.11.034 
R.G. Harrison, K.L. Aplin, F. Leblanc, Y. Yair, Space Sci. Rev. 137, (2008)

R.G. Harrison, M.H.P. Ambaum, Proc. Roy. Soc. Lond. A 464, 2561 (2008)

R.G. Harrison, H. Tammet, Space Sci. Rev. 137, 107 (2008)

R.G. Harrison, K.A. Nicoll, Atmos Res 89, 181 (2008)

doi:10.1016/j.atmosres.2008.01.008

R.G. Harrison, M.H.P. Ambaum, J. Atmos. Sol. Terr. Phys. 72, 1408 (2010)

R.G. Harrison, I. Usoskin, J. Atmos. Sol. Terr. Phys. 72, 176 (2010)

R.G. Harrison, K.Aplin, M. Rycroft, J. Atmos. Sol. Terr. Phys. 72, 376 (2010)

R.G. Harrison, M.H.P. Ambaum, M. Lockwood, Proc. Roy. Soc. A, 464, 2561 (2011) doi10.1098/rspa2011.0040

M. Hayakawa, K. Ohta, A.P. Nickolaenko, Y. Ando, Ann. Geophys. 23, 1335 (2005)

M. Hayakawa, A.P. Nickolaenko, M. Sekiguchi, K. Yama shita, Y. Ida, M. Yano, Nat. Hazards Earth Syst. Sci. 8, 1309 (2008)

M. Hayakawa, Nat. Hazards Earth Syst. Sci. 11, 301 (2011)

P.B. Hays, R.G. Roble, J. Geophys. Res. 84A, 3205 (1979)

A. Hirsikko, T. Niemenen, S. Gagne, K. Lehtipalo, H.E. Manninen, M. Ehn, U. Horrak, V.-M. Kerninen, L. Laakso, P.H. McMurry, A. Mirme, T. Petaja, H. Tammet, V.

Vakkari, M. Vana, M. Kulmala, Atmos. Chem. Phys. 11, 767 (2011)

R.H. Holzworth, J. Atmos. Terr. Phys. 43, 1115 (1981)

E.A. Kasatkina, O.I. Shumilov, M.J. Rycroft, F. Marcz, A.V. Frank-Kamanetsky, Atmos. Phys. Chem. Discuss. 9, 21941, 10, 24015 (2010)

M.C. Kelley, The Earth's ionosphere: Plasma physics and electrodynamics, second edition, Elsevier, Amsterdam (2009)

N.G. Kleimenova, O.V. Kozyreva, M. Kubicki, S. Michnowski, Geomagnetism and Aeronomy 50, 48 (2010)

D.R. Kniveton, B.A. Tinsley, G.B. Burns, E.A. Bering, O.A. Troshichev, J. Atmos. Sol. Terr. Phys. 70, 1633 (2008) 
M. Kokorowski, J.G. Sample, R.H. Holzworth, E.A. Bering, S.D. Bale, J.B. Blake, A.D. Collier, A.R.W. Hughes, E. Lay, R.P. Lin, M.P. McCarthy, R.M. Millan, H. Moraal, T.P. O’Brien, G.K. Parks, M. Pulupa, B.D. Reddell, D.M. Smith, P.H. Stoker, L. Woodger, Geophys. Res. Lett. 33, L20105 (2006) doi:10.1029/2006GL027718

G. Kondo, Memoirs of the Kakioka Magnetic Observatory 13, 11 (1968)

M.N. Kulkarni, J. Geophys. Res. 114, D06107 (2009) doi:10.1029/2008JD010009

C.P.A. Kumar, C. Panneerselvam, K.U. Nair, K. Jeeva, C. Selvaraj, S. Gurubaran, R. Rajaram, Indian J. Radio and Space Res. 37, 39 (2008)

C. Lao, E.R. Williams, E.J. Zipser, G. Burns, J. Atmos. Sci 67, 309 (2010) doi:10.1175/2009JAS3248.1

G. Lu, R.J. Blakeslee, J. Li, D.M. Smith, X.-M. Shao, E.W. McCaul, D.E. Buechler, H.J. Christian, J.M. Hall, S.A. Cummer, Geophys. Res. Lett. 37, L11806 (2010) doi:10.1029/2010GL043494

D.M. Mach, R.J. Blakeslee, M.G. Bateman, J.Geophys. Res. 116, D05201 (2011) doi10.1029/2010JD014462

M. Makino, T. Ogawa, J. Atmos. Terr. Phys. 46, 431 (1984)

M. Makino, T. Ogawa, J. Geophys. Res. 90, 5961 (1985)

F. Marcz, J. Atmos. Sol. Terr. Phys. 59, 975 (1997)

F. Marcz , P. Bencze, J. Atmos. Sol. Terr. Phys. 60, 1435 (1998)

R. Markson, Nature 320, 588 (1986)

R. Markson, Bull. Am. Meteorol. Soc. 88, 223 (2007)

C.E. McIlwain, J. Geophys. Res. 66, 3681 (1961)

J. Miller, Phys. Today 64, 16, January (2011)

V.A.Mullayarov, V.I. Kozlov, A.A. Toropov, R.R. Karimov, J. Atmos. Solar-terr. Phys. 72, 409 (2010)

K. Nakamura and particle data group, J. Phys. G Nucl. Part. Phys. 37, 075021(2010) doi10.1088/0954-3899/37/7A/075021

T. Nakamura, M. Sekiguchi, Y. Hobara, M. Hayakawa, J. Gophys. Res. 115, A00E39 (2010) doi :10.1029/2009JA014992 
F. Nemec, O. Santolik, M. Parrot, J. Geophys. Res. 114, A04303, doi:10.1029/2008JA013972

A.P. Nickolaenko, M. Hayakawa, Y. Hobara, Surv. Geophys. 31, 409 (2010)

K.A. Nicoll, PhD thesis, University of Reading (2010)

K.A. Nicoll, R.G. Harrison, J. Atmos. Sol. Terr. Phys. 71, 2040 (2009)

K.A. Nicoll, R.G. Harrison, Geophys. Res. Lett. 37, L13802 (2010) doi10.1029/2010GL043605

A.F.L. Nogueira, IEEE Latin America Trans. 7, 223, (2009)

A.Odzimek, M. Lester, M. Kubici, J.Geophys. Res. 115, D18207 (2010) doi10.1029/2009JD013341

T. Palmer, P. Williams (eds), Stochastic physics and climate modelling, Cambridge (2010)

V.P. Pasko, J. Geophys. Res. 115, A00E35 (2010) doi10.1029/ 2009JA014860

V.P. Pasko, Y. Yair, C.-L. Kuo, This volume (2011)

C. Price, Geophys. Res. Lett. 20, 1363 (1993)

C. Price, in M. Fullekrug, E.A. Mareev, M.J. Rycroft (eds), 85 (2006)

C. Price, O. Pechony, E. Greenberg, J. Lightning Res. 1, 1 (2007)

S. Pulinets, D. Ouzounov, J. Asian Earth Sci. 41, 371 (2010)

V.A. Rakov, M.A. Uman, Lightning: physics and effects, Cambridge (2003)

C.D. Reeve, M.J. Rycroft, J. Atmos. Terr. Phys 34, 667(1972)

H. Rishbeth, O.K. Garriott, Introduction to ionospheric physics, Academic, New York, London (1969)

J.A. Riousset, V.P. Pasko, P.R. Krehbiel, W. Rison, M.A. Stanley, J. Geophys. Res. 115, A00E10 (2010) doi:10.1029/2009JA014286

R.G. Roble, J. Geophys. Res. 90, 6000 (1985)

R.G. Roble, P.B. Hays, J. Geophys. Res. 84, 7247 (1979) 
R.G. Roble, I. Tzur, in The Earth's electrical environment, 206, National Academy Press, Washington, DC (1986)

R.G. Roble, J. Atmos. Sol. Terr. Phys. 53, 831 (1991)

C.J. Rodger, M. Cho, M.A. Clilverd, M.J. Rycroft, Geophys. Res. Lett. 28, 199 (2001)

A.Rouillard, M. Lockwood, Ann. Geophys. 22, 4381 (2004)

R. Roussel-Dupre, J.J. Colman, E. Symbalisty, D. Sentman, V.P. Pasko, Space Sci. Rev. $137,51(2008)$

M.J. Rycroft, S. Israelsson, C. Price, J. Atmos. Sol. Terr. Phys 62, 1563 (2000)

M.J. Rycroft, J. Atmos. Sol. Terr. Phys. 68, 445 (2006)

M.J. Rycroft, A. Odzimek, N.F. Arnold, M. Fullekrug, A. Kulak, T. Neubert, J. Atmos. Sol. Terr. Phys. 69, 2485 (2007)

M.J. Rycroft, R.G. Harrison, K.A. Nicoll, E.A. Mareev, Space Sci. Rev. 137, 83 (2008)

M.J. Rycroft, A. Odzimek, AIP Conf. Proc. 1118, 124 (2009)

M.J. Rycroft, A. Odzimek, J. Geophys. Res. 115, A00E37 (2010) doi10.1029/2009JA014758

M.J. Rycroft, The plasma and radiation environment in Earth orbit, in Encyclopedia of Aerospace Engineering, R. Blockley, W. Shyy (eds), eae323, Wiley, Chichester (2010) doi10.1002/978040686652

B.K. Sapkota, N.C. Varshneya, J. Atmos. Terr. Phys. 52, 1 (1990)

B. Schwarzchild, Phys. Today 64, 10, May (2011)

A.V. Shvets, M. Hayakawa, Surv. Geophys. 32, in press (2011)

A.V. Shvets, M. Hayakawa, M. Sekiguchi, Y. Ando, J. Atmos. Solar-terr. Phys. 71, 1405 (2009)

A.V. Shvets, Y. Hobara, M. Hayakawa, J. Geophys. Res. 115, A12316 (2010) doi10.1029/2010JA015851

D. Siingh, R.P. Singh, A.K. Kamra, P.N. Gupta, R. Singh, V. Gopalakrishnan, A.K. Singh, J. Atmos. Sol. Terr. Phys. 67, 637 (2005) 
D. Siingh, V. Gopalakrishnan, R.P. Singh, A.K. Kamra, S. Singh, V. Pant, R. Singh, A.K. Singh, Atmos. Res. 84, 91 (2007)

D. Siingh, R.P. Singh, A.K. Singh, M.N. Kulkarni, A.S. Gautam, A.K. Singh, Surv. Geophys. 32, in press (2011)

F. Simoes, M. Rycroft, N. Renno, Y. Yair, K.L. Aplin, Y. Takahashi, Space Sci. Rev. 137,455 (2008)

J. Slingo, K. Bates, N. Nikiforakis, M. Piggott, M. Roberts, L. Shaffrey, I. Stevens, P.L. Vidale, H. Weller, Phil. Trans. R. Soc. A 367, 815 (2009)

D. M. Smith, AIP Conf Proc 1118, 34 (2009)

D.M. Smith, B.J. Hazelton, B.W. Grefenstette, J.R. Dwyer, R.H. Holzworth, E.H. Lay, J.Geophys. Res. 115, A00E49 (2010) doi:10.1029/2009JA014853

A.J. Smith, R.B. Horne, N.P. Meredith, J. Atmos. Sol. Terr. Phys. 72, 463 (2010)

M.A. Stanley, X.-M. Shao, D.M. Smith, L.I. Lopez, M.B. Pongratz, J.D. Harlin, M. Stock, A. Regan, Geophys. Res. Lett 33, L06803 (2006) doi10.1020/2005GL025537

E.K. Stansbery, A.A. Few, P.B. Geis, J. Geophys. Res. 98, 16,591 (1993)

Y.I. Stozhkov, V.I. Ermakov, V.S. Makhmutov, Proc. ICRC 2001, 4157 (2001)

J.N. Thomas, R.H. Holzworth, M.P. McCarthy, Atmos. Res. 91, 153 (2009)

doi:10.1016/j_atmosres.2008.03.026

B.A. Tinsley, J.T. Hoeksema, D.N. Baker, J. Geophys. Res. 99(D8), 16,805 (1994)

B.A. Tinsley, G.B. Burns, L. Zhou, Adv. Space Res. 40, 1126 (2007)

B.A. Tinsley, Rep. Prog. Phys. 71, 066801 (2008) doi:10.1088/0034-4885/71/6/066801

J. F.Valde's-Galicia, R. Pe'rez-Enrı'quez, J.A. Otaoloa, Solar Phys. 167, 409 (1996) (doi:10.1007/BF00146349)

P.I.Y. Velinov, A. Mishev, L. Mateev, Adv. Space Res. 44, 1002 (2009)

H. Volland, Phys. Scr. T18, 289 (1987)

B. Vonnegut, Ann. Rev. Earth and Planet. Sci. 1, 297 (1973) 
T. Whitely, M. Fullekrug, M. Rycroft, A. Bennett, F. Wyatt, D. Elliott, G. Heinson, A. Lewis, R. Sefako, P. Fourie, J. Dyers, A. Thomson, S. Flower, Radio Sci. 46, RS4007 (2011) doi: 10.1029/2010RS004523

J.C. Willett, J. Geophys. Res. 84(C8), 4999 (1979)

E.R. Williams, Science 256, 1184 (1992)

E.R. Williams, Encyclopedia of Atmospheric Sciences, ed. J.R. Holton, J.A. Pyle, J.A. Curry, 724, Academic, San Diego (2002)

E.R. Williams, Y. Yair, in M. Fullekrug, E.A. Mareev, M.J. Rycroft (eds), 57 (2006)

E.R. Williams, Atmos. Res. 91, 140 (2009)

E.R. Williams, R. Boldi, J. Bor, G. Satori, C. Price, E. Greenberg, Y. Takahashi, K. Yamamoto, Y. Matsudo, Y. Hobara, M. Hayakawa, T. Chronis, E. Anagnostou, D.M. Smith, L. Lopez, J. Geophys. Res. 111, D16209 (2006) doi:10.1029/2005JD006447

E.R. Williams, W.A. Lyons, Y. Hobara, V.C. Mushtak, N. Ascencio, R. Boldi, J. Bor, S.A. Cummer, E. Greenberg, M. Hayakawa, R.H. Holzworth, V. Kotroni, J. Li, C. Morales, T.E. Nelson, C. Price, B. Russell, M. Sato, G. Satori, K. Shirahata, Y. Takahashi, K. Yamashita, Q. J. R. Meteorol. Soc. 136, S1, 257 (2010) doi :10.1002/qj.489

C.T.R. Wilson, Proc. Camb. Philos. Soc.,13, 363 (1906)

C.T.R. Wilson, Philos. Trans. R. Soc. Lond. A 221, 73 (1921)

C.T.R. Wilson, J. Franklin Inst. 208, 1 (1929)

C.T.R. Wilson, Proc. Roy. Soc. Lond. A 236, 297 (1956)

K. Yamashita, Y. Takahashi, M. Sato, H. Kase, J. Geophys. Res. 116, A00E61 (2011) doi:10. 1029/2009JA014792

H. Yeng, V.P. Pasko, G. Satori, J. Geophys. Res. 114, D01103 (2009) doi10.1029/2008JD009961

L. Zhou, B.A. Tinsley, J. Atmos. Sci. 671143 (2010) 


\section{Figures with captions}

Figure 1

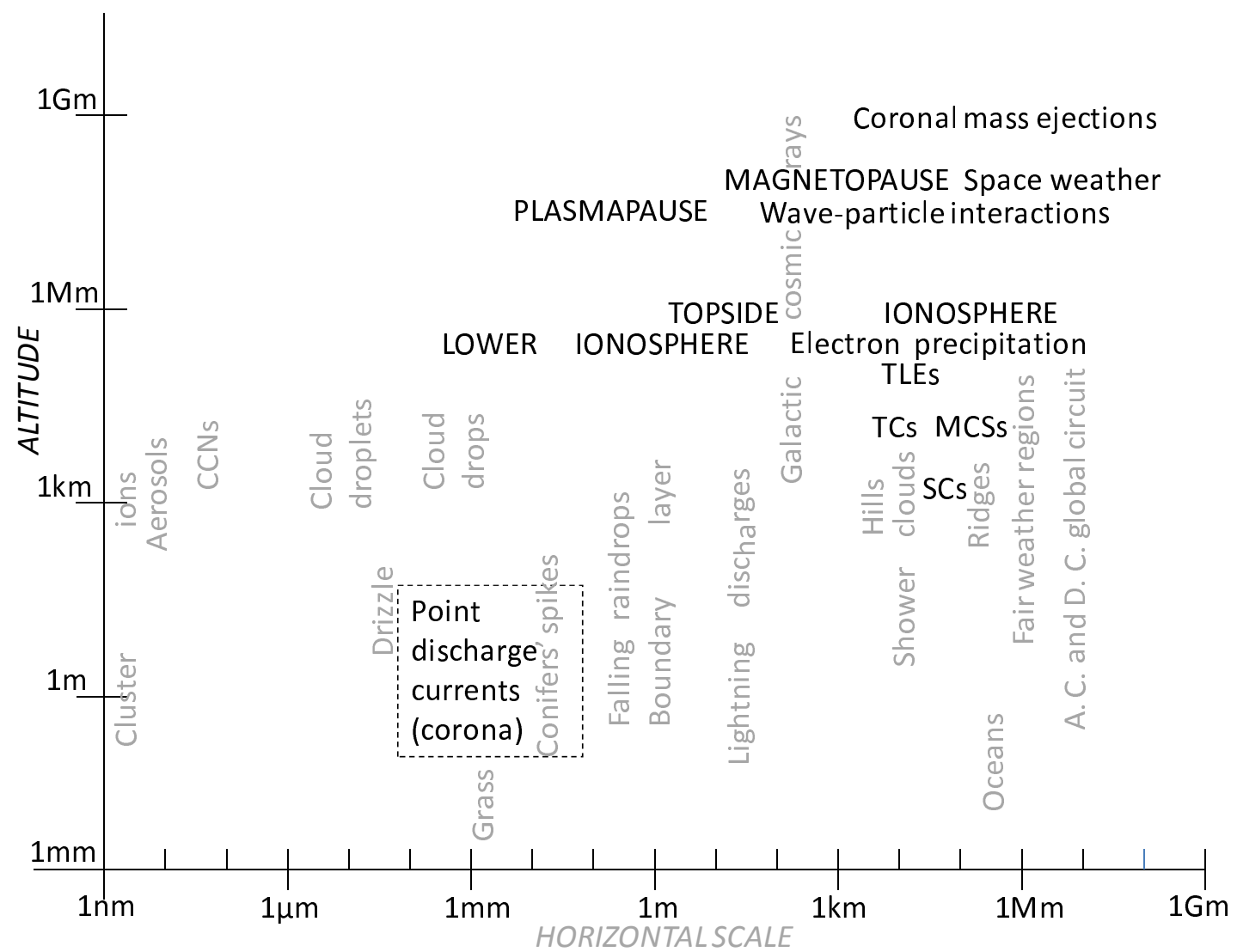

Fig. 1. Diagram indicating the very large range of horizontal and vertical scales involved in various electrical phenomena of interest in the Earth's atmosphere and near-Earth space environment. Words appearing horizontally show different regions at different altitudes where different physical processes make their presence felt and Words appearing vertically show features with a certain horizontal scale which are important over the altitude range indicated. (Here, TCs is an abbreviation for thunderclouds - other such terms are explained in the text.) 
Figure 2

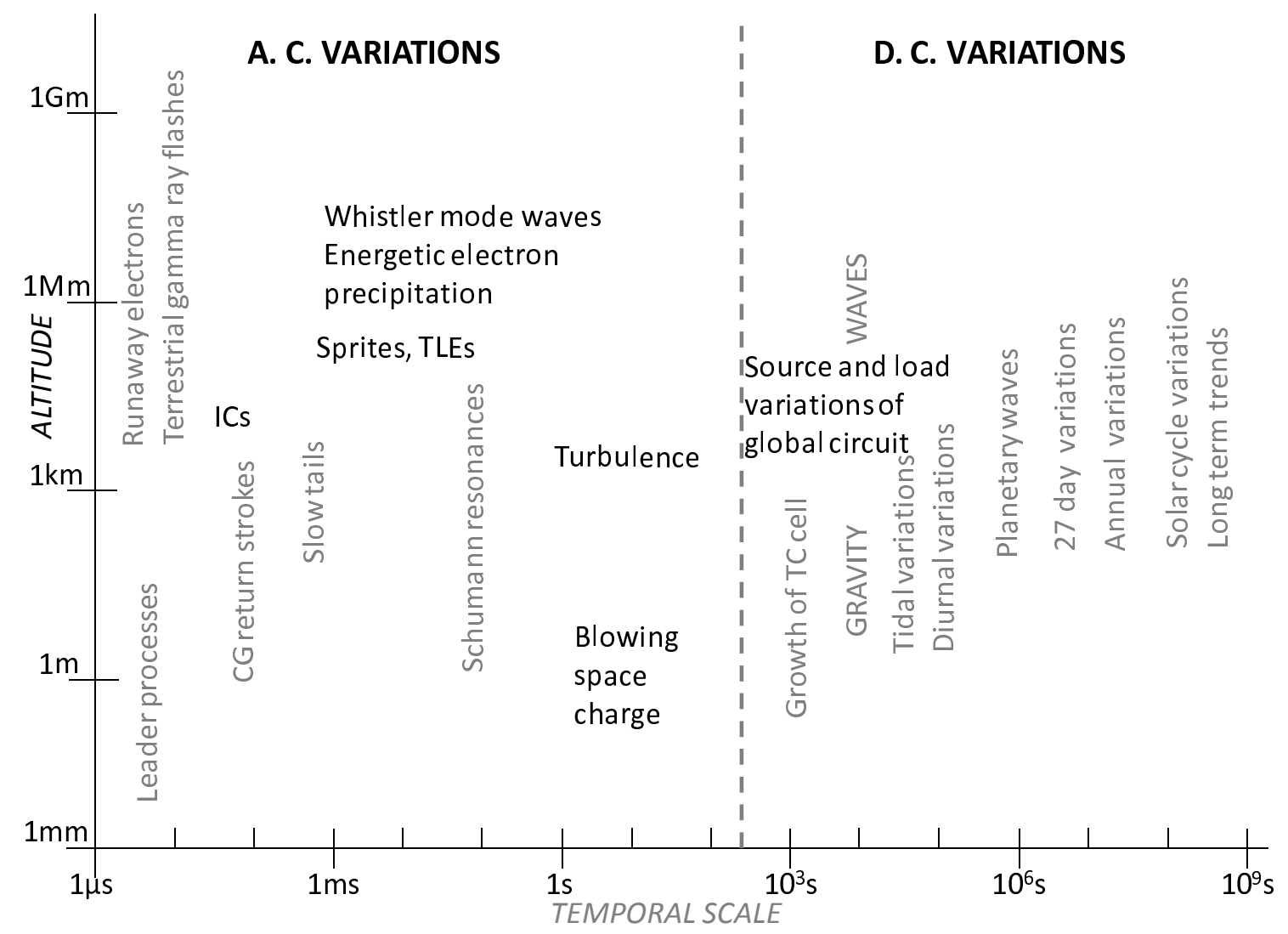

Fig. 2. Diagram showing the enormous range of time scales involved in important processes (horizontal words) occurring at different altitudes. Vertical words represent different phenomena which occur on different temporal scales over different altitude ranges - see the text for a fuller discussion. The boundary between A.C. and D.C. variations is placed at $\sim 200 \mathrm{~s}$, the RC time constant of the poorly conducting atmospheric region between the good conducting Earth and the ionosphere. 
Figure 3

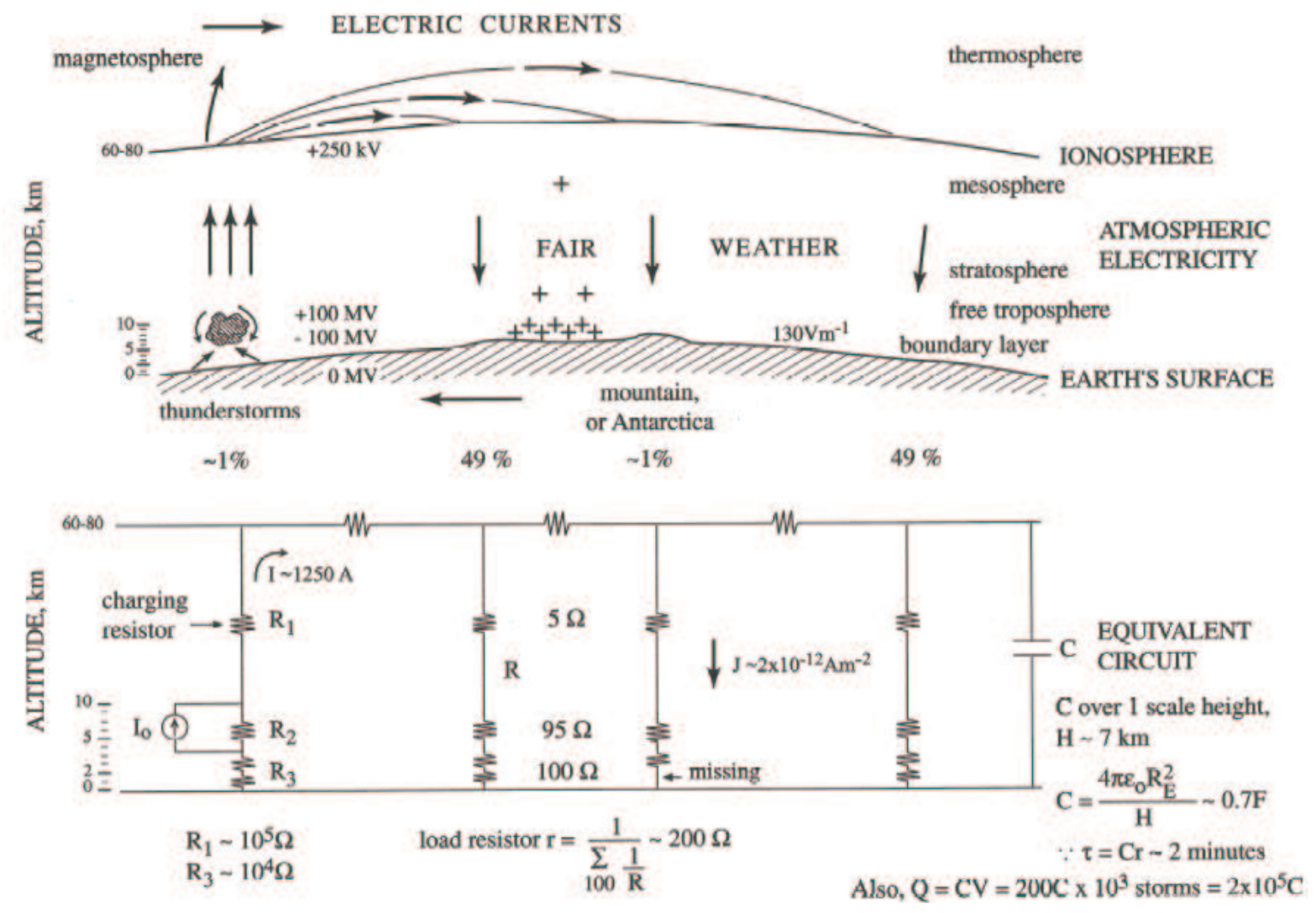

Fig. 3. Taken from Rycroft et al. (2000), the upper panel illustrates a part of the global atmospheric electric circuit. On the left is shown a representative thunderstorm, one of the $\sim$ thousand which are active at all times and which occur over only a small part of the Earth's surface. Huge potential differences are generated inside thunderclouds; acting as giant batteries, they drive an upward (Wilson) current to the ionosphere at an altitude of $80 \mathrm{~km}$. The ionosphere is essentially an equipotenial surface at $\sim+250 \mathrm{kV}$ with respect to the Earth's surface, but small currents reach up into the magnetosphere. In fair weather regions remote from thunderstorms, over most of the Earth's surface, downward currents $\sim 2 \mathrm{pA} / \mathrm{m}^{2}$ flow vertically (radially) to the ground. Much more positive charge resides near the Earth's surface than in the stratosphere or mesosphere, as indicated by the density of the + symbols. The lower panel outlines a simple electrical engineering representation of the circuit. Over mountainous regions, the atmospheric columnar resistance is much less than it is elsewhere. Values for the $\mathrm{RC} \mathrm{(or} \mathrm{Cr}$ ) time constant are shown at the lower right. 
Figure 4
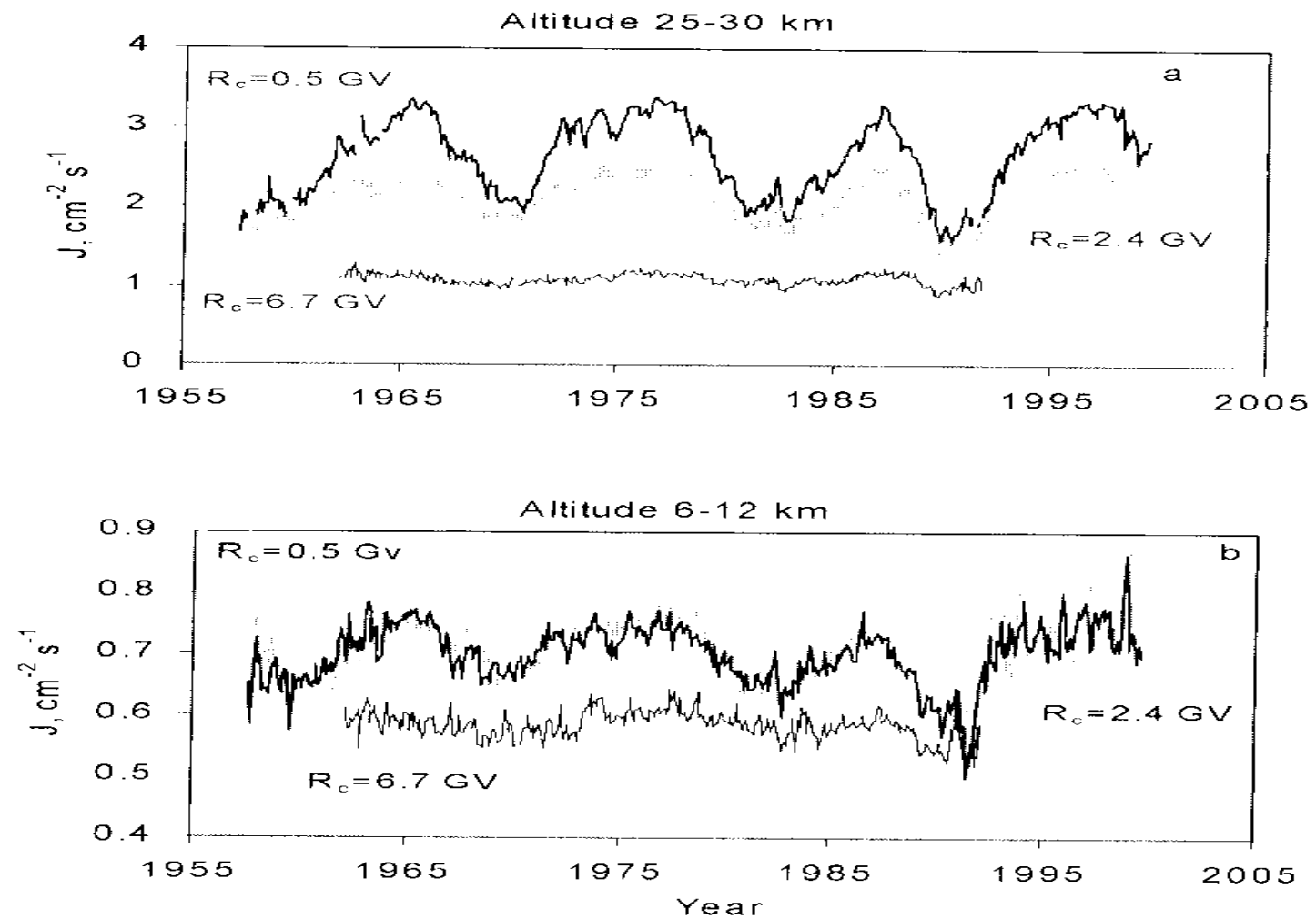

Fig. 4. Taken from Bazilevskaya et al. (2000), the upper (lower) panel plots the monthly average values of the omnidirectional flux of cosmic rays $J$ at altitudes between 25 and $30 \mathrm{~km}(6$ to $12 \mathrm{~km})$ at geomagnetic latitudes of 33 degrees (cut-off rigidity $\mathrm{R}_{\mathrm{c}}=6.7 \mathrm{GV}$ ), 51 degrees $(2.4 . \mathrm{GV})$ and 64 degrees $(0.6 \mathrm{GV})$, showing a clear 11 year solar cycle variation. 
Figure 5

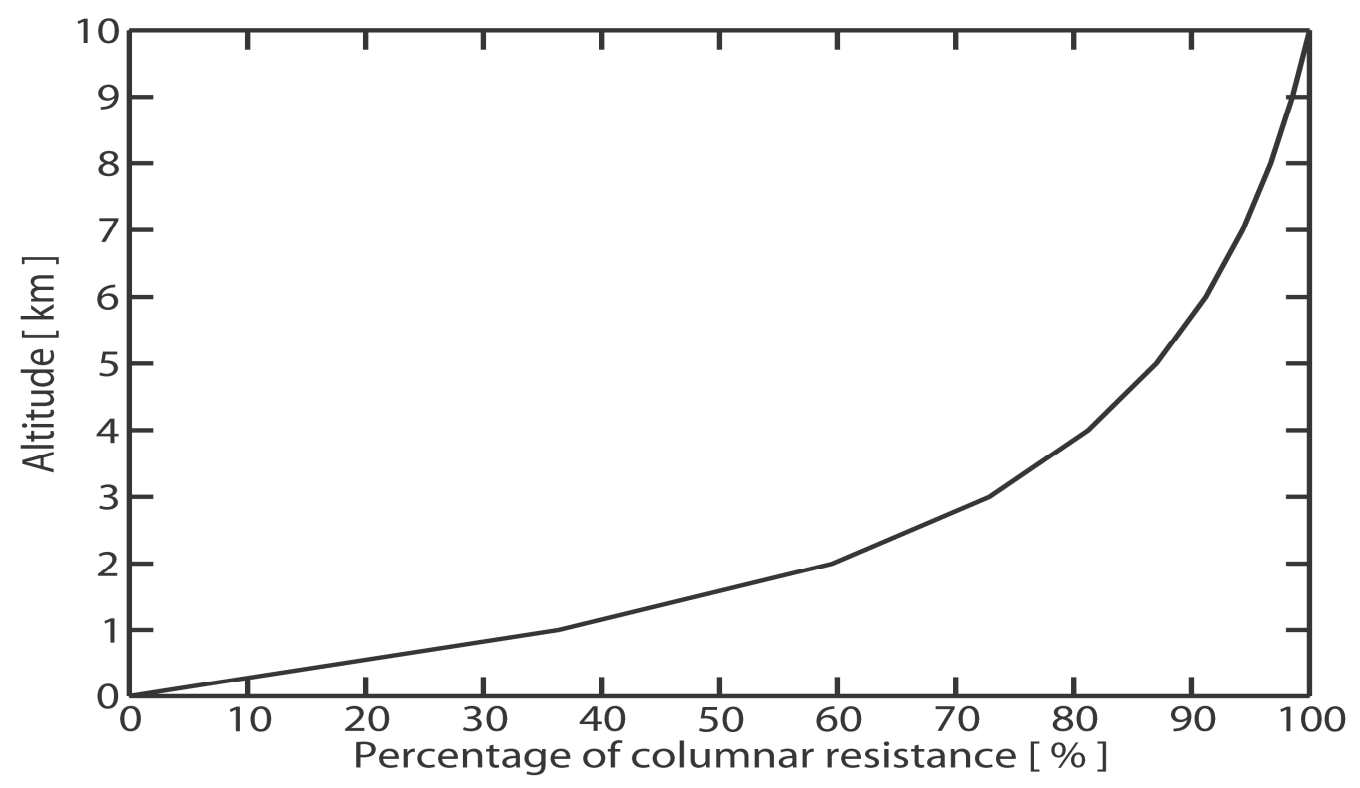

Fig. 5. The variation of the percentage of the columnar resistance up to $10 \mathrm{~km}$ altitude in fair weather regions, for the model atmospheric conductivity profile given by Rycroft et al. (2008). About $93 \%$ of the total resistance from the ground up to the ionosphere at 80 $\mathrm{km}$ altitude is at altitudes below $10 \mathrm{~km}$ (taken from Rycroft et al 2008). 
Figure 6
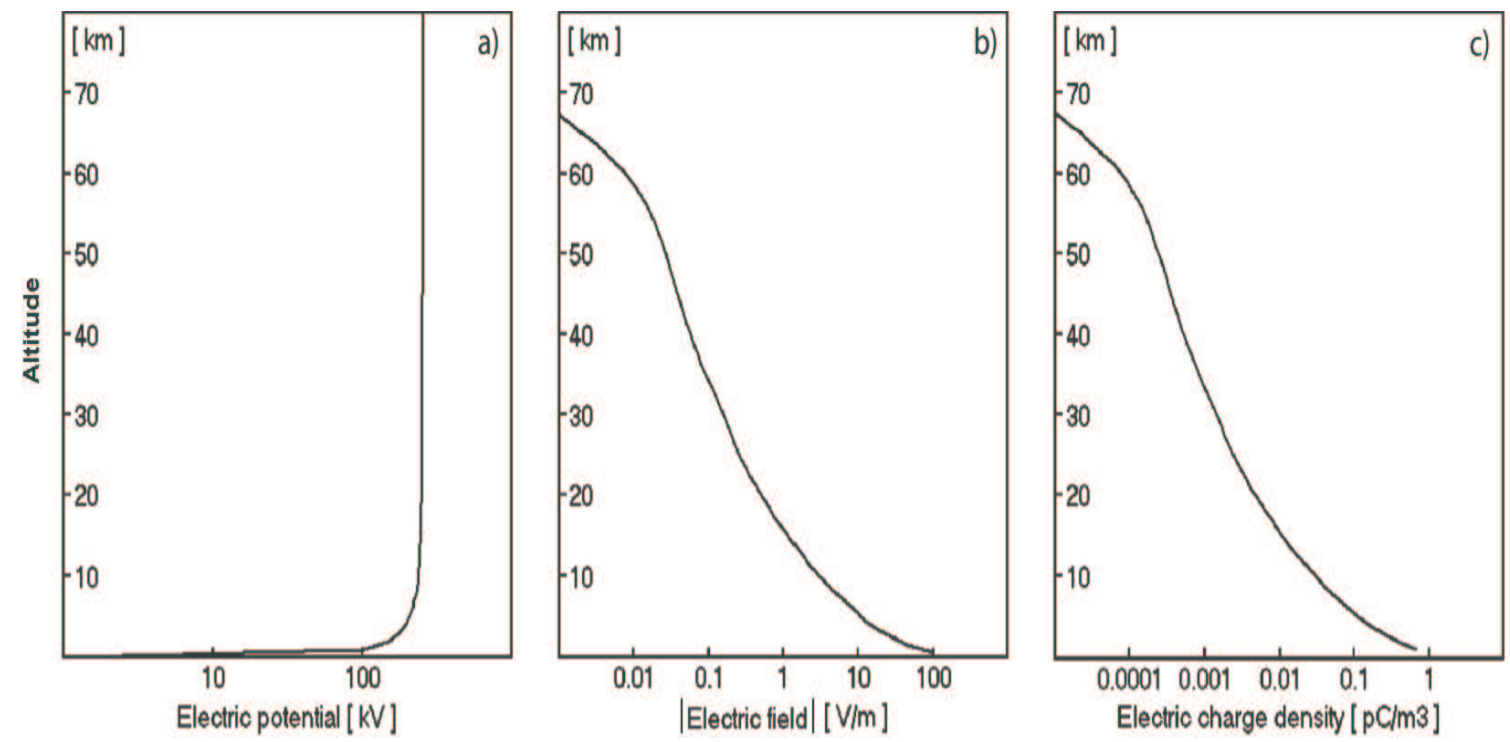

Fig. 6. In fair weather regions of the Earth's atmosphere are plotted the variation with altitude of (a) the electric potential, (b) the downward electric field, termed the potential gradient (PG), and (c) the electric charge density, taken from the model of Rycroft et al (2007). 
Figure 7

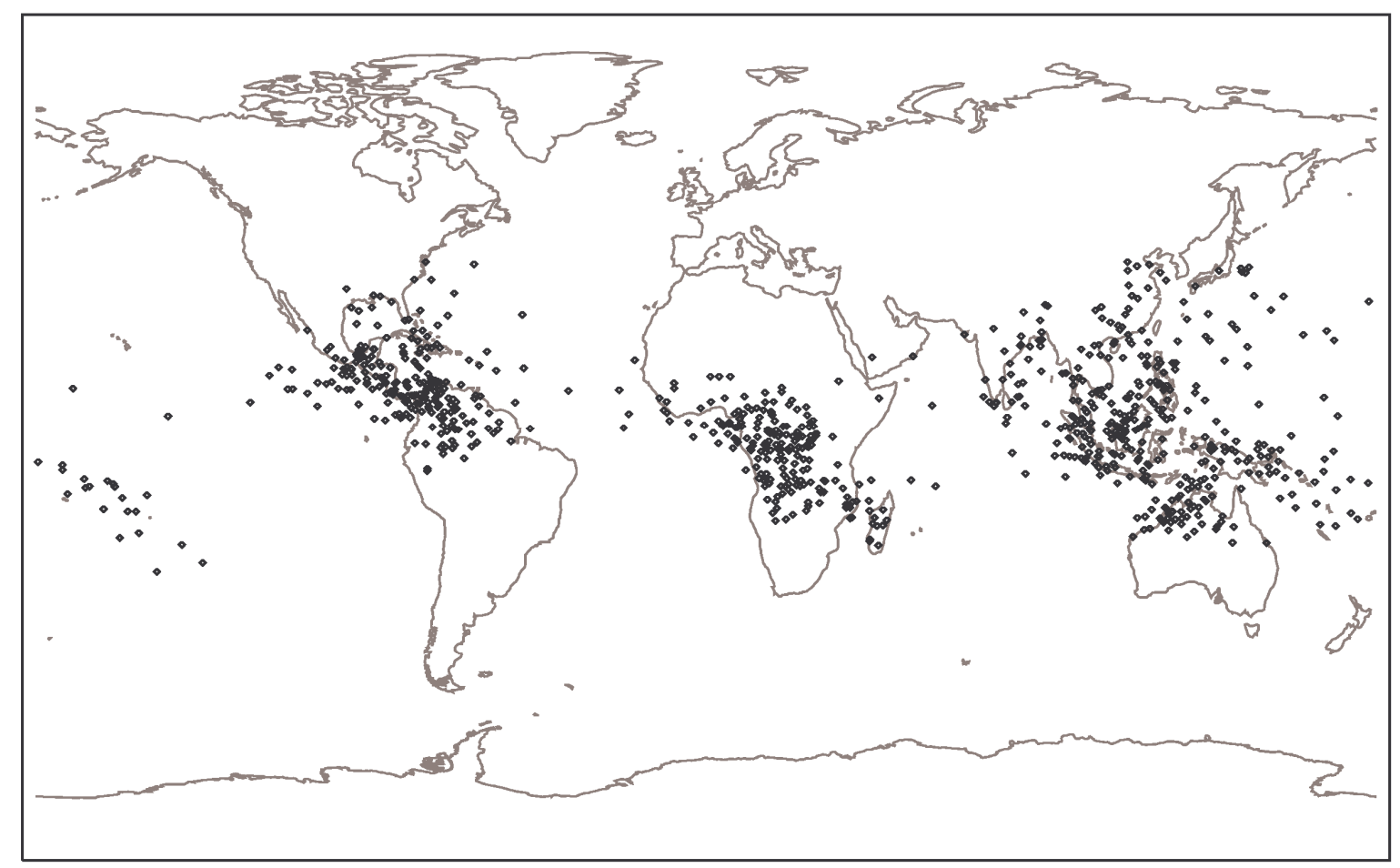

Fig. 7. Map showing the positions of the RHESSI satellite when its instrument observed terrestrial gamma-ray flashes (TGFs) - the TGF itself may occur a few hundred km from the dot shown. There are no dots at latitudes above 38 degrees, the orbital inclination of the satellite. The dots are concentrated in the tropics, but not over Brazil, the region of the South Atlantic Geomagnetic Anomaly (SAGA), where the instrument is disabled due to the presence of a high radiation dose from the inner Van Allen belt (taken from Smith 2009). 
Figure 8

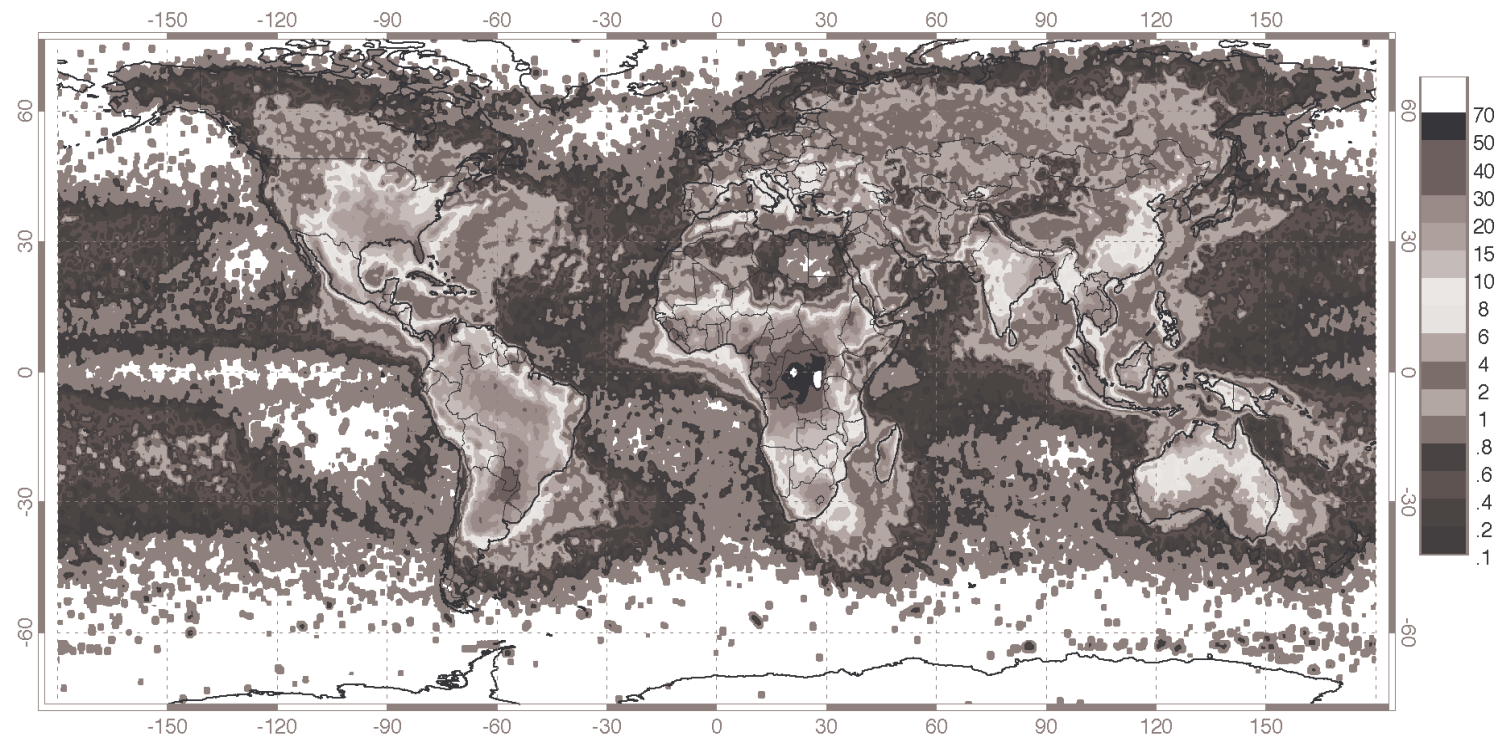

Fig. 8. Map showing the positions of lightning discharges, in number of flashes per $\mathrm{km}^{2}$ per year, as observed in the infrared part of the spectrum by the Optical Transient Detector (OTD) and Lightning Imaging Sensor (LIS) instruments on two Earth-orbiting satellites. The lightning is concentrated over the three tropical land masses, with rather few occurring over the tropical oceans, taken from National Space Science and Technology Center (NSSTC), Huntsville, Alabama, USA, data (taken from http://www.science.nasa.gov). 
Figure 9

(a)

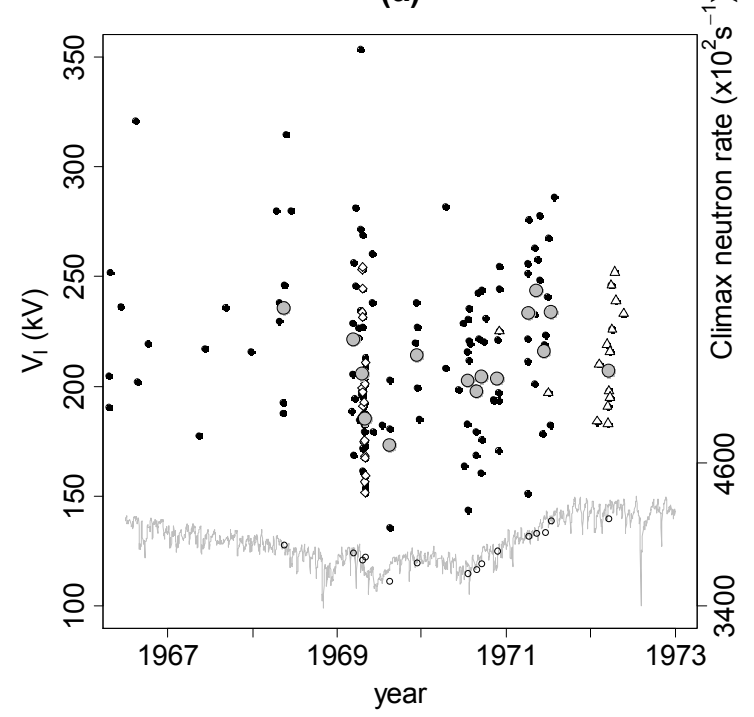

(b)

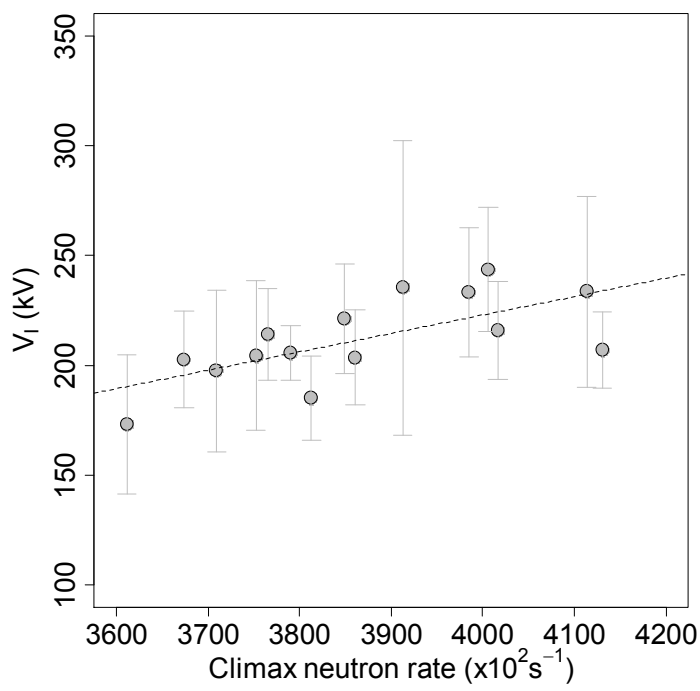

Fig. 9. Taken from Harrison and Usoskin (2010), the left panel (a) shows the ionospheric potential $\left(\mathrm{V}_{\mathrm{i}}\right)$ from various data sets, with larger circles showing monthly averages for months having four or more $\mathrm{V}_{\mathrm{i}}$ values, and the neutron count rate at Climax, Colorado, as the grey line, observed from 1966 to 1972 . The right panel (b) plots the monthlyaveraged $\mathrm{V}_{\mathrm{i}}$ values against the monthly average neutron count rate; the error bars show \pm two standard errors. 
Figure 10

(a)

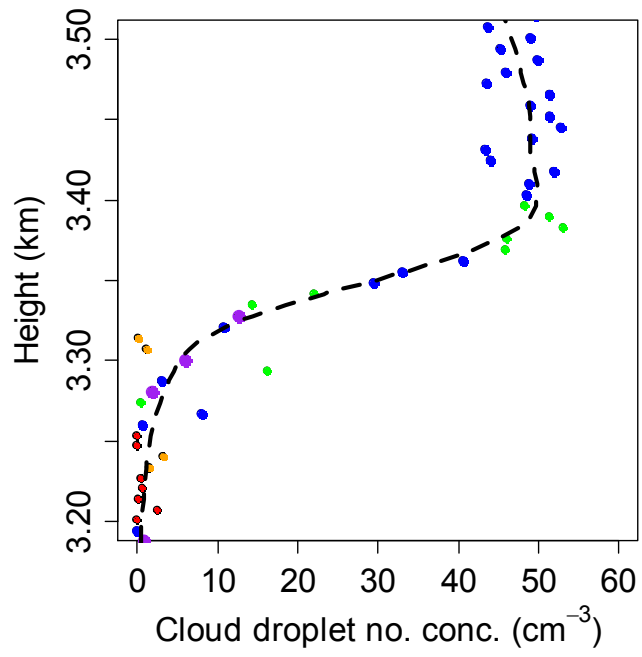

(c)

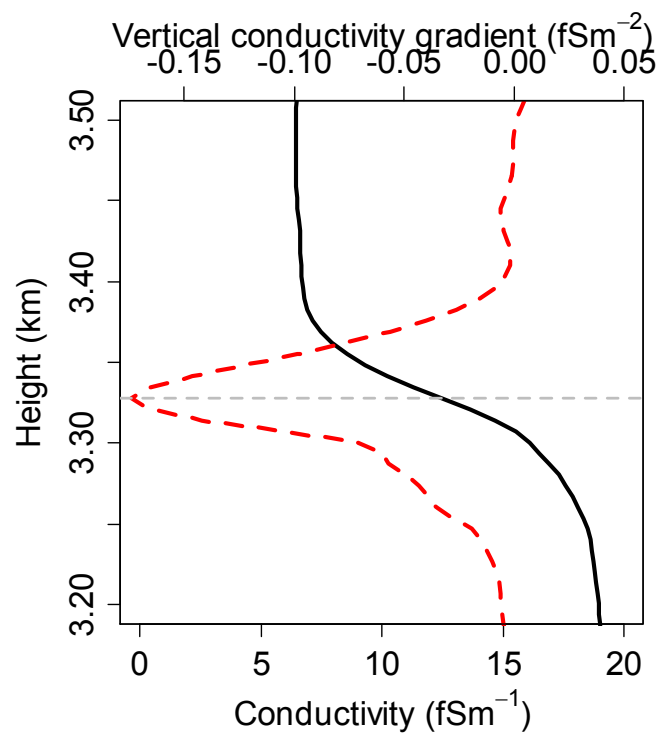

(b)

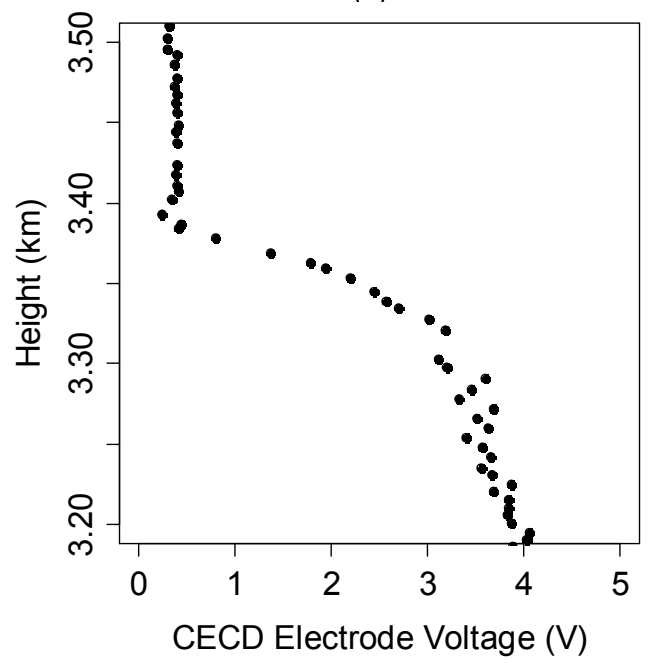

(d)

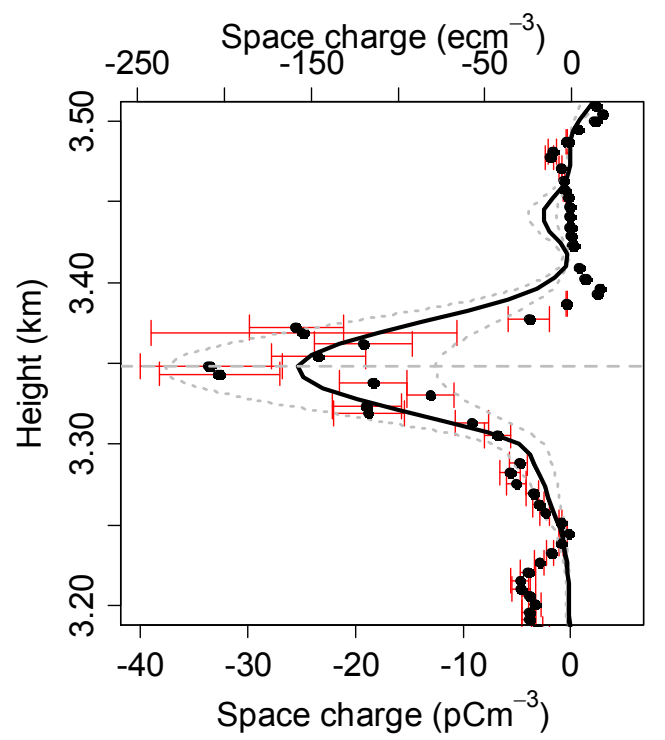

Fig 10. Observations are shown of atmospheric electricity parameters and deduced electric charges at the lower edge of a low-level stratiform cloud at heights from 3.2 to $3.5 \mathrm{~km}$, taken from Nicoll and Harrison (2010). Panel (a) shows the number concentration of cloud droplets, with an interpolating spline curve. Panel (b) plots the electrode voltage of a balloon-borne cloud edge charge detector (CECD); panel (c) shows the calculated conductivity (solid curve) in $\mathrm{fSm}^{-1}$ (lower scale) from the droplet concentrations, and the vertical conductivity gradient (dashed line curve, upper scale). Panel (d) shows the space charge density derived from the sensor voltages (points, with uncertainty), and the calculated space charge density, for a range of conduction current density assumptions (dashed line, solid line and dotted lines). The altitude of the space charge maximum, at $3.35 \mathrm{~km}$, is shown by the grey dashed horizontal line. 
Figure 11

(a)

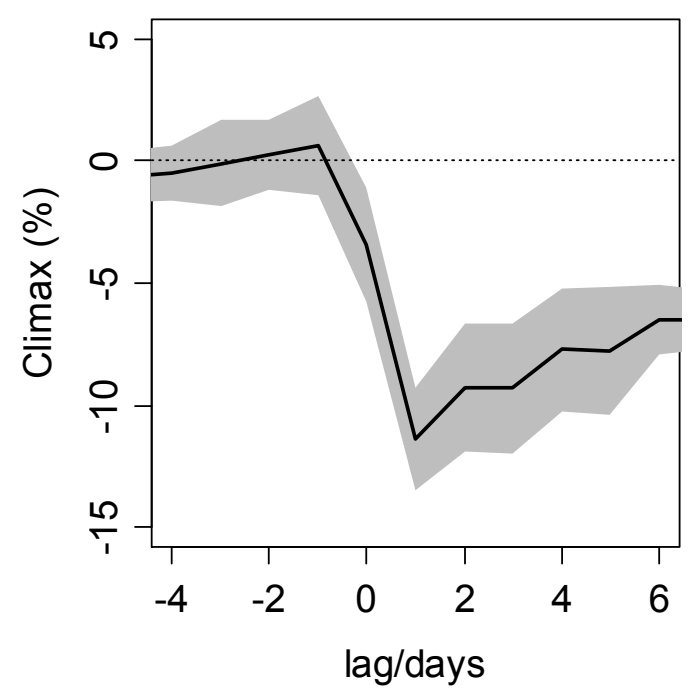

(b)

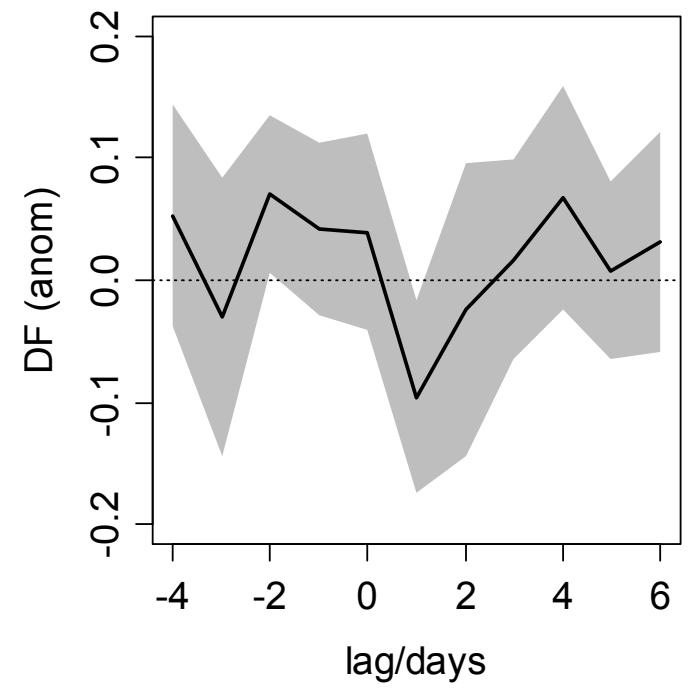

Changes in (de-seasonalised) Lerwick diffuse fraction (DF, a measure proportional to cloud) around Climax neutron counter decreases of $10 \%$ or greater. (a) Median of neutron counter changes of $10 \%$ or greater (black line) (b) Median anomalies in diffuse fraction (black line) for the same times. For both (a) and (b), the 95\% confidence range has been shaded. 
Figure 12
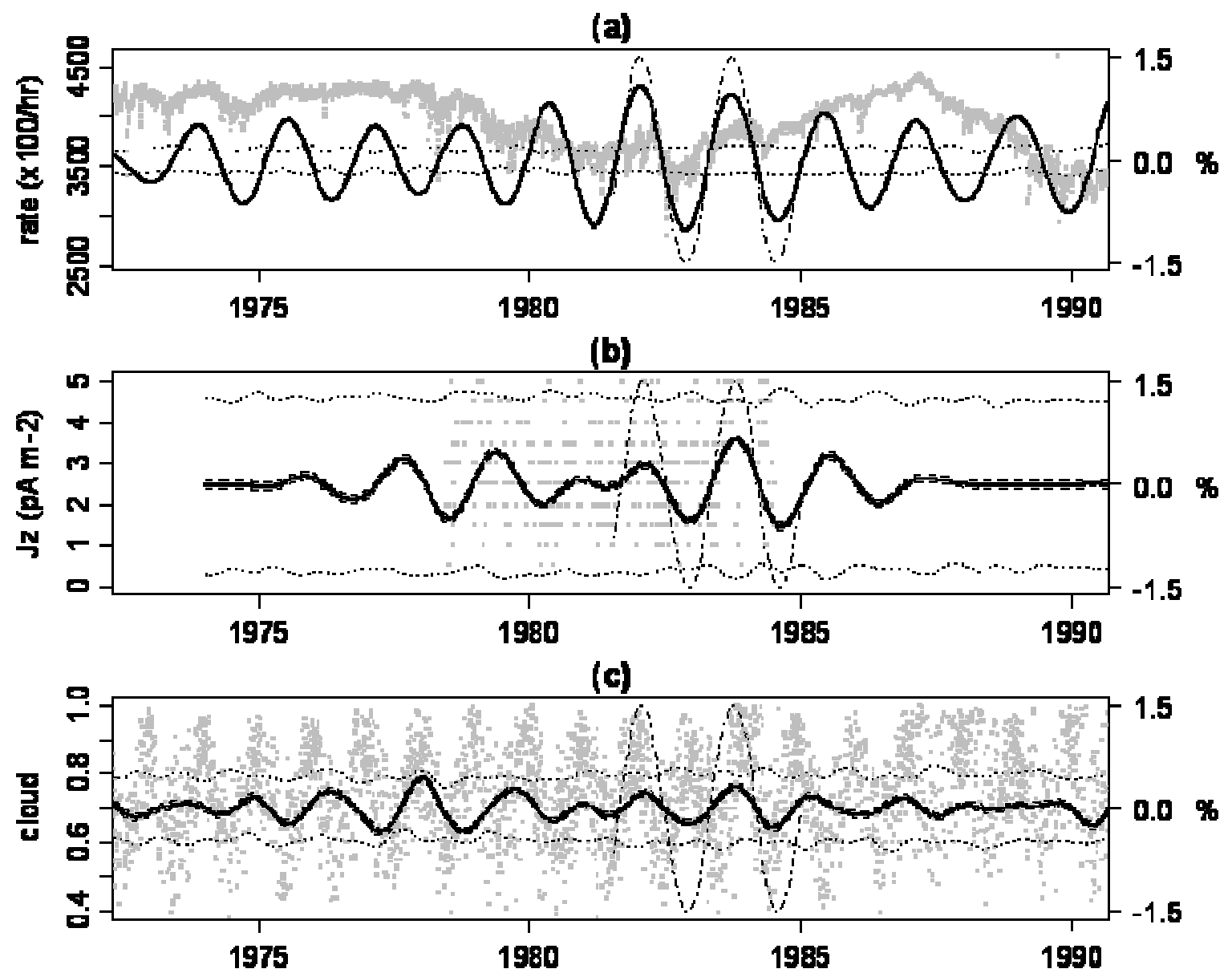

Daily raw (grey points) and filtered (black lines) data for (a) Climax neutrons, (b) Lerwick conduction current density (c) Lerwick cloud "thickness" (opaqueness) on overcast days. The black lines represent the bandpass filtered versions of the raw data, passband 1.55 to 1.81 years with phase relationships preserved, as a percentage of the mean value of the raw data. Randomly selected points from the relevant series have been substituted for missing data, and the mean filtered version (thick line) is determined from multiple realisations of the random data replacements, with $95 \%$ confidence limits shown (dashed lines). Dotted thin lines show the $95 \%$ confidence limits on the variability in multiple realisations obtained by passing randomly chosen points through the bandpass filter. Dashed-dotted lines show a fitted sine wave with period 1.68 years, beginning at 1981.5. The median phase angles for the duration of the fitted sine wave are (a) $166 \pm 0.2$ degrees, (b) $153 \pm 6$ degrees and (c) $160 \pm 6$ degrees, with the $95 \%$ confidence range found from fitting to each of the multiple realisations. 